J. Linguistics 58 (2022), 269-305. (C) The Author(s), 2021.

Published by Cambridge University Press. This is an Open Access article, distributed under the terms of the Creative Commons Attribution licence (http://creativecommons.org/licenses/by/4.0/), which permits unrestricted re-use, distribution, and reproduction in any medium, provided the original work is properly cited.

doi: $10.1017 /$ S0022226721000190

\title{
Local versus long-distance bound implicit arguments of inalienable relational nouns in Chinese $^{1}$
}

\author{
ALAN HEZAO KE \\ Michigan State University \\ ACRISIO PIRES \\ University of Michigan, Ann Arbor
}

(Received 30 October 2018; revised 28 February 2021)

This paper argues that inalienable relational nouns in Mandarin Chinese, specifically kinship nouns (KNs, e.g. father, sister) and body-part nouns (BPNs, e.g. head, face), have an implicit reflexive argument. Based on a syntactic comparison between KNs, BPNs, locally and longdistance bound reflexives, we argue that the implicit reflexive arguments of BPNs must be locally bound, whereas that of KNs can either be locally or long-distance bound. We conclude that these two types of implicit arguments in Mandarin Chinese correspond to locally and long-distance bound reflexives, respectively. We analyze this difference in connection with binding theory and a theory of logophoricity. We argue that the implicit argument of BPNs is a locally bound anaphor and cannot be used as a logophor, whereas that of KNs can, supporting a proposal that the logophoric property leads to long-distance binding, as argued by Huang \& Liu's (2001) for reflexives in Mandarin Chinese.

Keywords: binding, Chinese implicit argument, inalienable possession, logophor, reflexive

\section{INTRODUCTION}

In Mandarin Chinese (henceforth, Chinese), InAliEnABle RElational nouns (henceforth inalienable RNs), including KINSHIP NOUNS (KNs, e.g. father, aunt) and BODY PART NOUNS (BPNs, e.g. head, face), can generally occur as bare nouns without an overt possessor. While (1) below shows that the possessive argument of the KN son

[1] We thank the audiences at the 2018 Annual Meeting of the LSA in Salt Lake City, 20th Seoul International Conference on Generative Grammar (SICOGG 20) in Seoul, the Syntax Semantic Discussion Group at the University of Michigan and the MSU Language Acquisition Lab for their helpful comments. Special thanks go to the two anonymous referees and the editor (Hans van de Koot) of the Journal of Linguistics, Helge Lødrup, Samuel Epstein, Ezra Keshet, Tim Chou, Lucy Chiang, Zheng Shen, and Sze-Wing Tang for relevant discussion and suggestions. 
must be phonologically overt in English, ${ }^{2}$ otherwise the sentence is ungrammatical, (2a) indicates that bare RNs in Chinese are completely acceptable. Importantly, the interpretation of the sentence with a bare RN, i.e. (2a), is different from that with an overt pronominal possessor, seen in (2b). That is, the bare $\mathrm{RN}$ in (2a) must refer to Mary's son, whereas the pronominal possessor can refer either to Mary or to any other person salient in the context.

(1) $\operatorname{Mary}_{\mathrm{j}}$ sent $*\left(\right.$ her $\left._{\mathrm{j} / \mathrm{k}}\right)$ son to school.

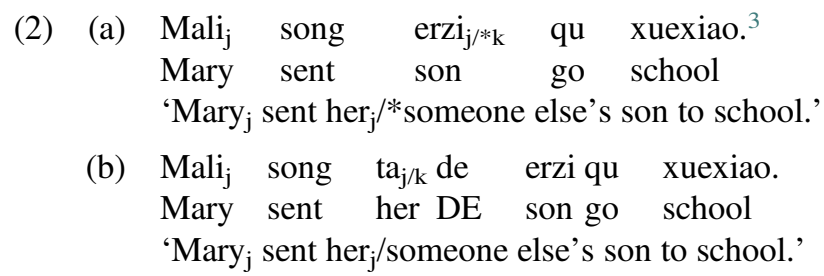

A main question we address in this paper is why in (2a) erzi 'son' must be Mary's son but not someone else's son, even if another possible possessor is salient in the context. (Considering the controversial status of $d e, b a$, and bei, which is not directly relevant to this paper, we take a neutral position and do not gloss them in the examples. For the purposes of the present paper, it suffices to say that $d e$ is, roughly, a possessive marker in all the examples discussed here, $b a$ is a head indicating that the following nominal is affected or manipulated in a certain way, and bei is generally a passive marker.)

If we assume that bare inalienable RNs such as KNs and BPNs have an implicit argument - a widely held assumption ( Partee 1983/1997, Barker 1995, Vikner \& Jensen 2002, Partee \& Borschev 2003, Zhang 2009) - several questions arise and we address them in this paper: What is the syntactic nature of this implicit argument in Mandarin Chinese? Is it a reflexive or a non-reflexive pronoun regarding its binding properties, considering how it relates to a particular antecedent and not others in different instances including (2)? Moreover, do KNs and BPNs bear the same type of implicit argument?

At first glance, a reasonable hypothesis is that inalienable RNs have a pronominal argument which refers to the possessor. This hypothesis is intuitive because when the possessor of an $\mathrm{RN}$ is overtly realized in examples parallel to (2), it is usually a possessive pronoun, as it is the case in the English counterpart (1).

[2] Only in some special cases can the possessive argument of RNs be omitted in English. For instance, in sentences such as (i) the bare KN mom is allowed. Accordingly, the interpretation of the $\mathrm{KN}$ in such cases is rather restricted: in this case it can only refer to the speaker's mother.

(i) Mom sent my sister home at $3 \mathrm{pm}$.

[3] In these and other examples below the indices on the RNs in the Chinese transcription are meant to identify the reference of their implicit argument, as shown on the English gloss. 
However, this paper provides evidence that the implicit argument of inalienable RNs must be a syntactically projected reflexive rather than a non-reflexive pronoun. Furthermore, a comparison of the implicit argument of KNs and BPNs to the monomorphemic/simple reflexive ziji 'self' and polymorphemic/complex reflexive taziji 'himself/herself' leads us to make a distinction between KNs and BPNs. We provide extensive evidence that the syntactic nature of their implicit arguments differs: the implicit argument of BPNs must be locally bound, whereas that of KNs can either be locally bound or long-distance bound. Finally, we will provide evidence that the long-distance bound implicit argument of KNs shows logophoric properties.

Given our extensive focus on this contrast, in what follows we use the term REFLEXIVE to refer to (overt or implicit) reflexives that are either locally or longdistance bound. We will also use the term ANAPHOR in reference to locally-bound anaphors/reflexives. Finally, our use of the term PRONOUN will make reference to non-reflexive pronouns that do not have to be bound. ${ }^{4}$

In this paper, we will restrict our discussion to two types of inalienable possession RNs - KNs and BPNs - and leave other types of RNs for future research.

This paper is organized as follows. Section 2 presents a literature review on the inalienable implicit/null argument of RNs in general and in Chinese in particular. In Section 3, we argue that the inalienable null argument of Chinese RNs is a reflexive that is syntactically projected. We then present several pieces of evidence for an important contrast between the null arguments of two types of RNs: the null argument of BPNs must be locally bound, whereas the null argument of KNs can be either locally or long-distance bound. Section 4 discusses several reasons why such a contrast exists and relates long-distance binding to the logophoric properties of the null argument of KNs. Section 5 provides three possible explanations for the binding and logophoric differences between BPNs and KNs. Finally, Section 6 concludes the paper.

\section{Literature REVIEW}

\subsection{Inalienability and implicit arguments of RNs}

We define RNs strictly as nouns which have an extra possessor argument. In other words, the relational meaning comes from RNs' lexical meaning (Barker 1995). This type of RNs is called inherent RNs in Partee's terminology (Partee \& Borschev 2003, Partee 2004, but see Asudeh 2005 for a broader definition). This is because this type of RNs have in their lexical meaning an inherent (implicit) argument, from which the RNs obtain their reference.

Regarding the semantic and syntactic representation of the implicit argument of RNs, previous studies in formal semantics agree that the implicit argument of RNs in general should be a pronominal variable, although it is still under debate whether this

[4] We avoided the use of the term 'pronominal' to refer to pronouns that do not have to be syntactically bound, to avoid confusion with some ambiguous uses of the attributive adjective 'pronominal' especially in our literature review. 
implicit argument is syntactically projected. One line of research including Partee (1983/1997) proposes an 'inherent R' to connect the implicit argument of RNs with another entity in the context (see also Vikner \& Jensen 2002 and Asudeh 2005). This inherent $R$ can connect the implicit argument to an entity salient in the context, which suggests that the implicit argument is pronominal. In that approach, this pronominal argument is not syntactically projected, but is instead only a semantic variable. Another line of research, including Stanley (2000, 2002, 2004), Stanley \& Szabó (2000) and Martí (2006, 2015), maintains the semantic-approach view that the implicit argument of an $\mathrm{RN}$ can link or refer to a salient entity in the context, but argues that this implicit arguments must be syntactically projected. In Stanley's (2000, 2002, 2004) approach, as long as an implicit argument has an effect on the truth-condition of an assertion, the argument must be present at LF, which is the 'real structure' of the assertion. Given that LF is where syntactic structures are interpreted, it follows that if an implicit argument has an effect on the truth-conditions of an assertion, it must also be present in the syntactic structure.

However, the syntactic presence of the implicit argument of inalienable RNs (primarily BPNs and KNs, and sometimes part-whole relations) is less controversial in previous studies. A wide range of studies on inalienable nouns across languages share the conclusion that inalienable nouns are associated with a syntactically present inalienable possessor as their inherent implicit argument (e.g. Alexiadou 2003 for Greek; Ritter \& Rosen 2014 for Blackfoot; Huang, Li \& Li 2009 and Niu 2016, among other studies that we return to in the next section, for Mandarin Chinese; and Guéron 1985, 2003, Vergnaud \& Zubizarreta 1992, and Nakamoto 2010, for French; see Chappell \& McGregory 1996 and Coene \& D'hulst 2003 for various other languages).

Body-part terms in French can be used without an explicit local possessor directly attached to them. Guéron (1985) argues that the syntactic constraints on inalienable BPNs in French, as listed in (3), are essentially the same as those on anaphoric binding.

(3) (a) The possessor of a BPN is obligatory.

(b) Locality constraint: the possessor must be in the same minimal argument domain as the BPN.

(c) Asymmetric c-command: the possessor must c-command the BPN or its trace. $^{5}$

(Guéron 1985: 47-48)

[5] However, French BPNs also require the realization of a definite determiner le/la/les, unlike Chinese bare RNs. Guéron $(1985,1992)$ assumes that the determiner in French is different from the in English, and argues that it is a PRO, which acts as an anaphor that must be locally bound if it is referential (otherwise it is a free variable optionally co-indexed with an arbitrary referent or an NP in its context). Guéron (2003) reanalyzes the determiner as a classifier that bears $\varphi$-features (number and gender), and proposes that the binding relation between the determiner and the possessor of the BPN is established by $\varphi$-feature agreement between these two. Questions arise regarding why determiners in RNs but not in other DPs/NPs would require external $\varphi$-feature agreement (yielding a binding relation). More importantly, given the absence of an overt determiner in Chinese bare RNs, this analysis cannot be directly applied to Chinese RNs. 
We will show in this paper that bare inalienable RNs in Chinese have similar properties regarding the requirement for a c-commanding possessor, although BPNs and KNs in Chinese split into two classes regarding their partially distinct locality requirements for this possessor antecedent.

\subsection{Chinese inalienable RNs}

It has been noted that inalienable RNs can occur in some special constructions in Chinese. Chappell (1996) discusses RNs in so called 'double subject constructions', exemplified in (4) (the structure projections are added by us).

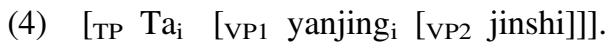
s/he eye short-sighted

'S/he is short-sighted.'

The observation is that inside VP1 there is another 'subject' argument in addition to the regular subject $t a$ 's/he'. Importantly, the third person singular pronoun $t a$ and the BPN yanjing 'eye' must be in an inalienable possession relation, that is, the eye must be hers/his, whoever the pronoun $t a$ 's/he' refers to, and not someone else's.

Notice that the two subjects are not necessarily adjacent to each other, as shown in (5a).

(5) (a) Ta zhi-shi yanjing you-xie jinshi.

s/he only-be eye have-little short-sighted

'S/he is just a little short-sighted.'

(b) $\mathrm{Ta}_{\mathrm{j}}$ hen nianqing. Zhi-shi $\mathbf{e}_{\mathrm{j}}$ yanjing yijing you-xie jinshi. s/he very young only-be eye already have-little short-sighted ' $\mathrm{S} / \mathrm{he}$ is very young. But $\mathrm{s} / \mathrm{he}$ is already a little short-sighted.'

In fact, the possessor can be implicit, linking to a referent established in the previous clause (5b), a possibility that we will address in our final discussion, after laying out our analysis of inalienable RNs. Therefore, Chappell (1996) suggests that the implicit possessor in such cases is a zero anaphor. Her corpus analysis further suggests that it must refer to an element within two clauses in the preceding context.

Cheng \& Ritter (1987: 72) provide an analysis for another type of inalienable possession construction, as in (6a), with the corresponding syntactic structure shown in (6b).

(6) (a) Ta ba juzi bo-le pi. s/he BA orange peel-ASP skin 'S/he skin-peeled the orange.' 
(b)

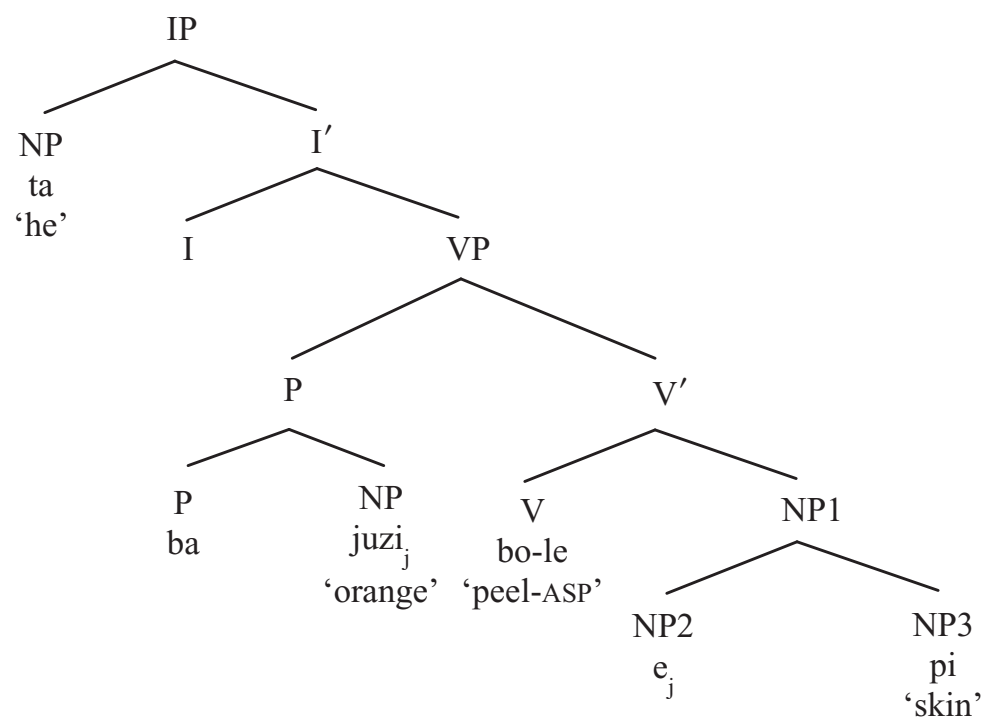

Cheng \& Ritter (1987) assume that an empty anaphor, $e$ in (6b), is projected inside the complex nominal NP1 and is bound by the complement of $b a$, juzi 'orange'. Cheng \& Ritter (1987) also assume that $b a$ is a preposition that assigns the theta-role of affected theme to its complement. This complement 'weak[ly] c-commands' the anaphor since the node immediately dominating it c-commands the anaphor (Huang 1982: 373). Although they provide no details regarding how the inalienable possessive relation comes into place between the null anaphor and the BPN pi 'skin', Cheng \& Ritter (1987) seem to consider the null anaphor an argument of the BPN, which they treat as a predicate.

The idea of taking the argument of an inalienable BPN as an anaphoric element is preserved in Huang et al.'s (2009: 140-147) discussion of still another type of possessive construction, the 'possessive passive' construction, as in (7).

(7) Zhangsan ${ }_{j}$ bei [IP OP tufei [ $\mathrm{VP}_{\mathrm{j}} \mathrm{t}_{\mathrm{j}}\left[\mathrm{v}^{\prime}\right.$ dasi-le ${ }_{\mathrm{NP}} \mathrm{Pro}_{\mathrm{j}}$ baba $\left.\left.]\right]\right]$. Zhangsan BEI bandits kill-ASP father

'Zhangsan had his father killed by the bandits.'

They assume that bei is a predicate that selects an experiencer subject Zhangsan and an IP denoting an event. The IP has an adjunct null operator OP controlled by the subject. For them, this control relation is realized under bei-predication. The OP, in turn, moves from the outer object of the VP dasi-le Pro baba, leaving a trace in the specifier of that VP. This trace, i.e. the VP specifier, is assigned the role affectee by the $V^{\prime}$. Finally, the trace of the OP controls the null Pro, which is the possessor of the inalienable RN baba 'father'. 
Huang et al. (2009) do not explain what a Pro is in their account, but refer readers back to Huang (1989). Huang (1989) discusses two types of empty categories, pro and PRO, so 'Pro' must be one of them. Huang (1989: 193) proposes that both pro and PRO are subject to a Generalized Control Rule, which implies that these two types of empty categories must be controlled in their control domain. The Generalized Control Rule and the control domain are respectively very similar to Binding Condition A and the binding domain in Chomsky $(1981,1986)$, suggesting that the Pro associated with the inalienable nouns in 'possessive passive' constructions such as (7) are treated similarly to a (locally-bound) anaphor.

Unlike the studies above, Niu (2016) assumes that the implicit argument of RNs, specifically KNs, is a null pro that is realized independently of whether there is an overt possessor (e.g. a pronoun) in the structure. Niu's syntactic structure for $t a$ $b a b a$ 'her/his father' is in (8).

ta baba 'her/his father' (see Niu 2016: 57)

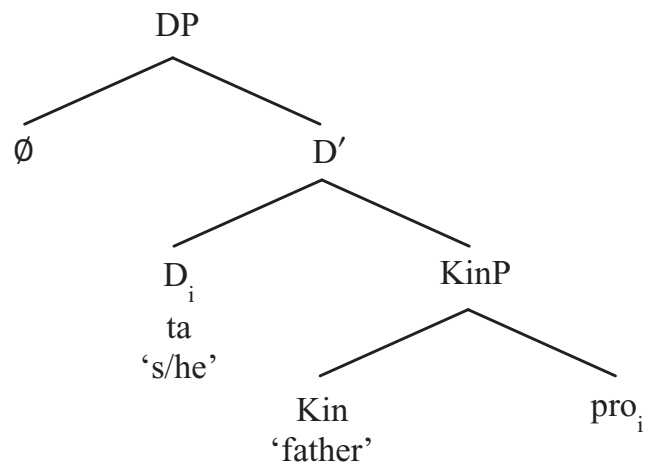

Niu (2016) proposes that in (8), the null pro agrees with the pronoun, which occupies the D head. Unfortunately, Niu (2016) does not explain why the null argument of KNs must be a pro. Since pro usually stands for a null pronoun, it is reasonable to assume that Niu treats it as a pronoun rather than a reflexive. Niu (2016: 60) also argues that BPNs do not have an implicit argument and are not RNs, contrary to what we will show in this paper. Finally, she restricts her analysis to what she refers to as juxtaposed possessives, such as ta baba 'her/his father' in (8), in which the possessor is overtly realized by a pronominal element with the DP projection of the RN.

In sum, Chappell (1996), Cheng \& Ritter (1987), Huang et al.'s (2009) and Niu (2016) treat the empty category associated with inalienable RNs in Chinese either as an anaphor which co-indexes with an antecedent (possibly through binding or control), ${ }^{6}$ or as a pronoun (normally a pro) which agrees and co-refers with its

[6] Such a proposal is similar to the binding approach to inalienable RNs in French (Guéron 1985, 2003), which we briefly mentioned above. 
antecedent. Therefore, the syntactic nature of the implicit argument of RNs remains controversial. In addition, these studies examine only special possessive constructions such as double subject constructions, $b a$-constructions and $b e i$-constructions, which seem to involve special theta-role assignments. For instance, the double subject constructions have two 'agents', and $b a$ - and bei-constructions include an affectee or an experiencer that is related to the possessor of the inalienable $\mathrm{RN}$. These constructions are not ideal for the study of implicit arguments of RNs, because in addition to binding/agreement/control, possessor raising/movement can also be involved, obscuring the syntactic nature of the implicit argument. Finally, and importantly, previous studies also do not recognize important syntactic differences between the implicit arguments of two types of inalienable RNs, namely BPNs and KNs, as we will do in this paper.

Therefore, we turn our attention back to inalienable RNs that occur as bare nouns heading an NP, as we specify below, which provide us cleaner empirical basis to investigate the syntactic nature of the implicit argument of RNs.

\section{The reflexive implicit argument of bare RNs in Chinese}

In this section, we explore the syntactic behavior of bare RNs in Chinese. First, we will review Ke et al.'s (2019) arguments that the implicit argument of kinship RNs must be a syntactically projected reflexive rather than a pronoun, based on their experimental results. We will provide additional empirical and theoretical evidence for this argument in this paper.

Ke et al. (2019) provide two pieces of experimental evidence for the argument that the implicit argument of bare kinship RNs is more likely a reflexive than a pronoun. First, participants in a truth-value judgment experiment judged test items such as (9) to be a false statement after hearing a story in which Zhangsan and Lisi planned to take their sons to the island Qingdao for a trip, and Zhangsan ended up taking Lisi's son but not his own son to Qingdao. The reason the participants provided to support their rejection of the sentence was that erzi 'son' in (9) must be Zhangsan's son, and not Lisi's son.

(9) Zhangsan dai-le erzi qu Qingdao.

Zhangsan take-ASP son go Qingdao

'Zhangsan took (his ${ }_{\text {Zhangsan/*Lisi }}$ ) son (to go) to Qingdao.'

Ke et al.'s (2019) experimental results such as above were compatible with the hypothesis that the implicit argument of RNs is a reflexive. If the implicit argument of the $\mathrm{RN}$ erzi 'son' is a reflexive, it must take the c-commanding subject Zhangsan as its antecedent, so the son must be Zhangsan's son. However, if the implicit argument were a pronoun, it could be related to a salient referent in the context, which would mean that the son could be Lisi's son in the interpretation of (9), contrary to what experimental subjects indicated. In addition, replacing the RN (in the background story and in the test sentence) with a non-RN, e.g. shubao 
'schoolbag', made the new test sentence, shown in (10), a true statement for the experimental subjects in Ke et al. (2019), who allowed shubao 'schoolbag' to be interpreted as Lisi's schoolbag, given the corresponding context story. Therefore, the interpretation of non-RNs in cases such as (10) shows that they do not have a reflexive argument, unlike RNs.
Zhangsan na-le shubao hui sushe.
Zhangsan take-ASP schoolbag return dormitory
'Zhangsan took (?Zhangsan/?Lisi's) schoolbag back to the dormitory.'

Second, Ke et al.'s (2019) experimental results showed that the referent of the implicit argument of kinship RNs observes a c-command requirement. That is, experimental subjects allowed only c-commanding NPs to be the antecedent of the implicit argument of RNs. For example, in (11), the son must be Mickey Mouse's son rather than Donald Duck's, because only Mickey Mouse c-commands the implicit argument of erzi 'son'.

$\begin{array}{lllllll}\text { (11) } & \text { Milaoshu }_{\mathrm{j}} & \text { [PP } & \text { zai } & \text { Tanglaoya }_{\mathrm{k}} & \text { zhuyuan } & \text { de shihou] dai-le } \\ \text { Mickey Mouse } & \text { at } & \text { Donald Duck } & \text { hospitalize } & \text { DE time } & \text { take-ASP } \\ \mathrm{e}_{\mathrm{j} / *_{\mathrm{k}}} & \text { erzi } & \text { qu } & & \text { xiaodao } & \text { lüyou. } & \\ & \text { aon } & \text { go } & & \text { small-island } & \text { travel }\end{array}$

'Mickey Mouse, at the time Donald Duck was hospitalized, took (Mickey's) son on a trip (to go) to the island.'

This c-command requirement for the co-reference reading is consistent with the hypothesis that the implicit argument is a reflexive, not a pronoun.

Therefore, Ke et al. (2019) proposed that kinship RNs in Chinese bear an implicit reflexive argument. Although Ke et al. did not exclude PRO as a possible candidate for the implicit argument of the bare RNs, PRO is arguably not possible in constructions such as (9) and (11), since these constructions are single clause CPs, not embedded clauses with a control subject. Therefore, we will not consider PRO in the analyses developed here (in our final discussion we return to further arguments for not adopting a PRO analysis of implicit arguments of RNs).

In what follows we provide additional empirical and theoretical arguments from quantifier binding and VP ellipsis to support the hypothesis that the implicit argument of bare RNs (including both KNs and BPNs) is a null reflexive rather than an unbound pronoun.

First, when a reflexive is bound by a quantifier, it allows only a bound reading, but a pronoun can have both a bound reading and a referential reading. In (12a) the BPN shou 'hand', or rather, its implicit argument, is bound by mei-ge xuesheng 'every student', and the sentence has a bound reading only: for every student $x, x$ wrote the answer on $x$ 's hand. ${ }^{7}$

[7] In this paper, we put aside a non-relational or arbitrary interpretation, where shou 'hand' in (12) can refer to a salient referent in the context, e.g. an artificial hand known to the speaker and the 
(12) (a) Mei-ge xuesheng $j_{j}$ dou ba da'an xie zai shou $\mathrm{j}_{\mathrm{j} / \mathrm{k}}$-shang. every-CLF student all BA answer write at hand-on 'Every student $\mathrm{j}_{\mathrm{j}}$ wrote the answer on (her/his $\mathrm{own}_{\mathrm{j} /{ }_{\mathrm{k}} \mathrm{k}}$ ) hand.'

(bound reading only)

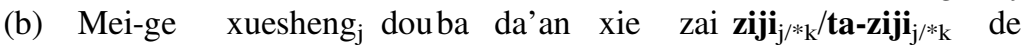
every-CLF student all BA answer write at self/her-/him-self DE shou-shang.

hand-on

'Every student $\mathrm{j}_{\mathrm{j}}$ wrote the answer on her/his own $\mathrm{j}_{\mathrm{j} / \mathrm{k}}$ hand.'

(bound reading only)

(c) Mei-ge xuesheng $\mathrm{j}_{\mathrm{j}}$ dou ba da'an xie zai ta $\mathrm{j}_{\mathrm{j} / \mathrm{k}}$ de shou-shang. every-CLFstudent all BA answer write at her/his DE hand-on 'Every student $\mathrm{j}_{\mathrm{j}}$ wrote the answer on her/his $\mathrm{j}_{\mathrm{j} / \mathrm{k}}$ hand.'

(bound and referential reading)

Similarly, as shown in (12b), if we insert an explicit reflexive possessor before the RN, i.e. ziji de 'self's' or ta-ziji de 'her/him-self's' (in boldface above), only the bound reading is available, matching the interpretation of the implicit argument of a BPN. However, (12c) shows that if instead a pronoun possessor (in boldface above) is inserted, the sentence becomes ambiguous, because besides the bound reading, shou 'hand' in (12c) can also refer to a possessor who is salient in the context and is not part of the set of students.

We also find that implicit arguments of RNs have interpretations matching those of reflexives, not pronouns, when RNs are elided inside a VP. It has long been known that elided bound reflexives have only a sloppy reading, whereas elided bound pronouns have both a strict and a sloppy reading, as in the contrast between (13a, b) (Sag 1976, Williams 1977, Shapiro \& Hestvik 1995, but see Hestvik 1995 for some variation).

(13) (a) John ${ }_{\mathrm{j}}$ defended himself $f_{\mathrm{j}}$, and Bill $\mathrm{k}_{\mathrm{k}}$ did [elided VP defend himself $\mathrm{*}_{\mathrm{j} / \mathrm{k}}$ ] too. (sloppy reading only)

(b) John likes his $_{\mathrm{j}}$ car and Bill $\mathrm{k}_{\mathrm{k}}$ does [elided VP like his ${ }_{\text {?j/k }}$ car] too.

(ambiguous)

(13a) means that John defended himself, and Bill also defended himself (sloppy reading). However, when a bound pronoun is elided in (13b), the sentence can mean that Bill likes John's car (strict reading) or his own (Bill's) car (sloppy reading). This is possibly because a pronoun can either be a bound variable or refer to a salient entity in the context, whereas a locally bound reflexive can only be a bound variable.

listeners. This is a case where the implicit argument of the BPNs is suppressed or saturated, following Barker (1995) and Zhang (2009). Similarly, KNs such as erzi 'son', father 'fuqin', shushu 'uncle', aunt 'ayi' can all be used as non-RNs. For example, in fuqin de zeren hen zhong 'the responsibility of a father is heavy', fuqin 'father' is not referentially dependent on a particular individual mentioned in the context; this is because the implicit argument of non-RNs is suppressed or saturated. 
With the pronoun and the reflexive interpreted as a bound variable, both $(13 \mathrm{a}, \mathrm{b})$ lead to the sloppy readings. However, the elided pronoun in (13b) can also refer to John, so the sentence has an additional interpretation, i.e. Bill likes John's car (strict reading).

When RNs such as toubu 'head' (14a) and fuqin 'father' (14b) are included in the elided VP, we find that only the sloppy reading is possible, regarding the interpretation of the RN's implicit argument.

(14) (a) Zongtong hui shouxian baohu toubu, Li Baobiao ye hui. President will primarily protect head Li Bodyguard also will 'The president ${ }_{\mathrm{j}}$ will primarily protect $\left(\mathrm{his}_{\mathrm{j}}\right.$ ) head, and Bodyguard $\mathrm{Li}_{\mathrm{k}}$ also will [primarily protect his $*_{\mathrm{j} / \mathrm{k}}$ head]. $\quad$ (sloppy reading only)

(b) Zhangsan hen huainian muqin, Lisi ye shi. Zhangsan very miss mother Lisi also is 'Zhangsan ${ }_{\mathrm{j}}$ missed $\left(\mathrm{his}_{\mathrm{j}}\right.$ ) mother very much, and Lisi ${ }_{\mathrm{k}}$ also [missed his $*_{\mathrm{j} / \mathrm{k}}$ mother].'

(sloppy reading only)

(c) Zhangsan bu zunjing Lisi de fuqin, Wangwu ye shi. Zhangsan not respect Lisi DE father Wangwu also is 'Zhangsan does not respect Lisi's father, and Wangwu also [does not respect Lisi's father].'

(strict reading only)

This indicates again that the implicit argument behaves as a reflexive rather than a pronoun (see Section 4, however, for our proposed split in the treatment of the implicit arguments of RNs as reflexives). In addition, if the possessor argument is saturated by an overt proper name, the sloppy reading under VP ellipsis is lost (14c).

The contrast is confirmed when we insert an overt reflexive or pronoun possessor before the RNs. If an overt reflexive possessor, ziji de "self's" or ta ziji $d e$ "himself's" (note that pronouns in Chinese do not make distinctions between genders), is attached to the RN in (14a), as shown in (15a), the interpretation of the sentence does not change. However, if a pronoun possessor, ta de 'his', is inserted (15b), either a sloppy or a strict reading is possible. The same applies to (14b), as shown in (16).

(15) (a) Zongtong hui shouxian baohu ziji/ta-ziji de toubu, Li Baobiao ye hui. 'The president $\mathrm{j}_{\mathrm{j}}$ will primarily protected his $\mathbf{o w n}_{\mathrm{j}}$ head, and Bodyguard $\mathrm{Li}_{\mathrm{k}}$ also [will primarily protect his own $*_{\mathrm{j} / \mathrm{k}}$ head].' (sloppy reading only)

(b) Zongtong hui shouxian baohu ta de toubu, Li Baobiao ye hui. 'The president $\mathrm{j}_{\mathrm{j}}$ will primarily protected $\mathbf{h i s}_{\mathbf{j}}$ head, and Bodyguard $\mathrm{Li}_{\mathrm{k}}$ also will [primarily protect his $\mathrm{j}_{\mathrm{j} / \mathrm{k}}$ head].' (ambiguous)

(16) (a) Zhangsan hen huainian ziji/ta-ziji de muqin, Lisi ye shi.

'Zhangsan ${ }_{\mathrm{j}}$ missed his own mother very much, and Lisi $_{\mathrm{k}}$ also [missed his own $*_{\mathrm{j} / \mathrm{k}}$ mother].'

(sloppy reading only) 
(b) Zhangsan hen huainian ta de muqin, Lisi ye shi.

'Zhangsan ${ }_{\mathrm{j}}$ missed his ${ }_{\mathrm{j}}$ mother very much, and Lisi ${ }_{\mathrm{k}}$ also [missed his $\mathrm{j}_{\mathrm{j} / \mathrm{k}}$ mother].'

(ambiguous)

\subsection{Bare BPNs bear locally bound reflexive arguments}

If the hypothesis that bare RNs have a reflexive argument is on the right track, a question immediately comes up: do body-part and kinship RNs have the same type of implicit reflexive argument? This question is important because Chinese has two types of reflexives, morphologically complex reflexives pronoun-ziji (e.g. ta-ziji 'her-/him-self') and morphologically simple reflexives (ziji 'self'). Complex reflexives are similar to English reflexives which must be locally bound in the minimal TP (or DP) with an accessible subject, where the reflexive is located (Chomsky 1986, Huang et al. 2009; see Yu 1996 and Pan 1998 for exceptions). ${ }^{8}$ On the other hand, the simple reflexive is a long-distance bound reflexive which allows a c-commanding antecedent in a higher TP. We show in this subsection that the implicit argument of BPNs shares with complex reflexives the requirement that both must be locally bound, whereas in Section 3.2 we show that the implicit argument of KNs behaves like the simple reflexive since both can be long-distance bound.

An important note should be made before we proceed: although we will argue that the implicit argument of BPNs is a locally bound reflexive, we do not commit to the conclusion that the implicit reflexive argument in this case must be a complex reflexive. The only reason we relate the implicit argument of BPNs to complex reflexives is because both happen to be locally bound (in canonical contexts).

Similar to complex reflexives, the implicit argument of bare BPNs in Chinese must be c-commanded and locally bound by its antecedent. In (17a) Zhangsan but not Lisi can be the antecedent of the implicit possessor argument of the BPN tui 'leg' because the former c-commands tui but the latter does not. Substituting tui with a complex reflexive $t a-z i j i$ 'her-/him-self' leads to the same restriction (17b).

(17) (a) Zhangsan ${ }_{j}$ [pP zai Lisi Z $_{\mathrm{k}}$ kanshu shi] zhuang-teng-le tui $\mathbf{j}_{\mathrm{j} / * \mathrm{k}}$. Zhangsan at Lisi read.book period bump-painful-ASP leg 'Zhangsan ${ }_{\mathrm{j}}$ bumped $\left(\mathrm{his}_{\mathrm{j} / * \mathrm{k}}\right)$ leg when Lisi $\mathrm{k}_{\mathrm{k}}$ was reading a book.'

(b) Zhangsan ${ }_{\mathrm{j}}\left[\mathrm{pP}\right.$ zai Lisi $\mathrm{k}_{\mathrm{k}}$ kanshu shi] zhuang-teng-le ta-ziji $\mathbf{j}_{\mathbf{j}} * \mathrm{k}_{\mathrm{k}}$. Zhangsan at Lisi read-book period bump-painful-ASP himself 'Zhangsan ${ }_{\mathrm{j}}$ bump himself $\mathrm{j}_{\mathrm{j} / \mathrm{k}}$ when Lisi $_{\mathrm{k}}$ was reading a book.'

[8] In this paper, we restrict ourselves to reflexives and RNs in canonical object positions, ignoring for instance their use in sentential subject (Spec, TP) positions or as intensifiers. Given certain exceptional properties of reflexives in those contexts (e.g. reflexives in sentential subject position are not expected to be bound in their local TP), we leave consideration of RNs in such positions for future research. 
The structure in (18a) shows that shou 'hand' must be locally bound, allowing only the local subject Lisi as its antecedent.
(a) Zhangsan Z $_{\mathrm{j}}$ yishi-dao $[\mathrm{TP}$ Zhangsan realize
Lisi $_{\mathrm{k}}$ kuai
Lisi soon
qie-dao $\quad$ shou $_{* j / k}$ le].
'Zhangsan ${ }_{\mathrm{j}}$ realized that Lisi $_{\mathrm{k}}$ is about to cut (his $*_{\mathrm{j} / \mathrm{k}}$ ) hand.' (local)
(b) Zhangsan ${ }_{\mathrm{j}}$ yishi-dao [TP Lisi $\mathrm{K}_{\mathrm{k}}$ kuai qie-dao ta-ziji *j/k $_{\mathrm{k}}$ de shou le].
(local)
(c) Zhangsan Z $_{\text {yishi-dao [TP Lisi }}$ kuai qie-dao ziji $_{\mathrm{j} / \mathrm{k}}$ de $\begin{gathered}\text { shou le]. } \\ \text { (ambiguous) }\end{gathered}$

This is similar to (18b), where a complex reflexive possessor is inserted before shou and the same interpretation is obtained. If we instead insert a simple reflexive ziji 'self' as the possessor in (18c), the sentence has a different interpretation; (18c) is now ambiguous in that the simple reflexive can be locally or long-distance bound.

\subsection{KNs bear long-distance bound reflexive arguments}

We have shown that BPNs bear a locally bound reflexive argument, now let us test KNs. If KNs had a locally bound reflexive argument, we would expect them to have the same distribution as BPNs. However, if KNs instead have a long-distance reflexive as their implicit argument, then we expect it to have the core, if not all, syntactic properties of the long-distance simple reflexive ziji. This latter prediction is borne out: the implicit argument of KNs shows the binding properties of a simple reflexive. In order to compare KNs with simple reflexives, we examine the syntactic properties in (19).

(19) (a) C-command requirement

(b) Long-distance binding

(c) Subject orientation

(d) Blocking effects

The list of properties in (19) have been identified as the most important syntactic characteristics of Chinese simple reflexives in the literature (e.g. Huang \& Tang 1991, Cole \& Sung 1994, Xue, Pollard \& Sag 1994, Pan 2001, Wang \& Pan 2015; see also Charnavel et al. 2017 for a comprehensive review). We have already shown the c-command requirement at the beginning of Section 3; below we focus on the three other properties.

\subsubsection{Long-distance binding}

Fuqin 'father' in (20a) can be either John's or Tom's father, which means that the implicit argument of father can be either locally or long-distance bound. We find that the interpretation is the same as $(20 \mathrm{~b})$, where an overt simple reflexive is 
inserted as the possessor of the $\mathrm{KN}$, unlike (20c), where a complex reflexive is added as the possessor.

(a) Yuehan $_{\mathrm{j}}$ zhidao $_{\mathrm{TP}}$ Tangmu $_{\mathrm{k}}$ hen aihu fuqin $\left.{ }_{\mathrm{j} / \mathrm{k}}\right]$. John know Tom very care.for father 'John ${ }_{\mathrm{j}}$ knows that Tom $\mathrm{k}$ takes good care of $\left(\right.$ his $_{\mathrm{j} / \mathrm{k}}$ ) father.' (ambiguous)

(b) Yuehanzhidao [TP Tangmu $\mathrm{k}_{\mathrm{k}}$ hen aihu $\mathbf{z i j i}_{\mathrm{j} / \mathrm{k}}$ de fuqin]. (ambiguous)

(c) Yuehanzhidao $\left[\mathrm{TP}_{\mathrm{T}}\right.$ Tangmu $_{\mathrm{k}}$ hen aihu ta-ziji ${ }_{* \mathrm{j} / \mathrm{k}}$ de fuqin].

The examples in (21) provide additional evidence showing a clear contrast between BPNs and KNs, because the two sentences differ minimally regarding whether a $\mathrm{BPN}$ or a $\mathrm{KN}$ is involved (as boldfaced). We find that the implicit possessor argument requires local binding with the BPN in (21a), but allows either local or long-distance binding with the $\mathrm{KN}$ in (21b).
(a) Zhangsan ${ }_{\mathrm{j}}$ yishi-dao [те Lisi K $_{\mathrm{k}}$ kuai nongshang shou $*_{\mathrm{j} / \mathrm{k}}$ le]. Zhangsan realize Lisi soon hurt hand SFP 'Zhangsan realized that Lisi $_{\mathrm{k}}$ is about to hurt (his $*_{\mathrm{j} / \mathrm{k}}$ ) hand.' (local)
(b) Zhangsan ${ }_{\mathrm{j}}$ yishi-dao [тP Lisi kuai nongshang fuqin ${ }_{\mathrm{j} / \mathrm{k}}$ le]. Zhangsan realize Lisi soon hurt father SFP 'Zhangsan ${ }_{j}$ realized that Lisi $_{k}$ is about to hurt $\left(\right.$ his $\left._{\mathrm{j} / \mathrm{k}}\right)$ father.'

(ambiguous)

\subsubsection{Subject orientation}

Although any NP that c-commands ziji can in principle be taken as its antecedent, there is a strong preference to take the subject rather than the object as the antecedent (Huang 1982, but see Huang et al. 2009 for exceptions). For example, in (22a), ziji refers to the subject Zhangsan rather than the object Lisi. Both Zhangsan and Lisi ccommand ziji, so it is surprising that only Zhangsan can be taken as the antecedent of ziji. We do not see such a strong subject-orientation effect for the complex reflexive (22b), but the pattern for KNs is similar to that of the simple reflexive (22c). ${ }^{9}$

[9] Huang \& Tang (1991) have a different intuition toward (22b), which they think exhibits subject orientation as well. They list another example of subject orientation with complex reflexives, which we cite here in (i).

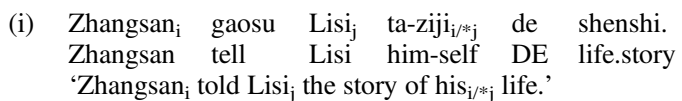

(Huang \& Tang 1991: 282)

Unlike Huang \& Tang (1991), we accept Lisi as the antecedent of ta-ziji in a context in which Lisi did not know much about his own life story (e.g. Lisi lost his memory) but Zhangsan knew that and told Lisi the story. In addition, if ta-ziji in (i) is replaced with ziji, we obtain a much stronger subjectorientation effect. Therefore, we maintain the view that the complex reflexive in Chinese, like its English counterparts, is not subject-oriented. 

(a) Zhangsan ${ }_{j}$ songgei-le Lisi ${ }_{k}$ yi-zhang ziji $/ *_{k}$ de zhaopian. Zhangsan give-ASP Lisi one-CLF self DE photo

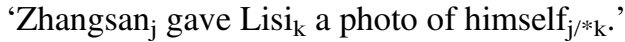
(b) Zhangsan ${ }_{\mathrm{j}}$ songgei-le Lisi $\mathrm{K}_{\mathrm{k}}$ yi-zhang ta-ziji $\mathrm{j}_{\mathrm{j} / \mathrm{k}}$ de zhaopian. Zhangsan give-ASP Lisi one-CLF himself DE photo
(c) Zhangsan ${ }_{j}$ songgei-le Lisi ${ }_{k}$ yi-zhang erzi $j_{j} / *_{k}$ de zhaopian. Zhangsan give-ASP Lisi one-CLF son DE photo 'Zhangsan ${ }_{\mathrm{j}}$ gave $\mathrm{Lisi}_{\mathrm{k}}$ a photo of $\left(\mathrm{his}_{\mathrm{j} / * \mathrm{k}}\right)$ son.'

On the other hand, (23a) shows that the BPN lian 'face' is not subject-oriented. (23b) further shows that the interpretation is similar to the overt complex reflexive possessor case, which is also not subject-oriented, rather than the overt simple reflexive possessor case.

(a) Zhangsan ${ }_{j}$ gei Lisi $_{k}$ hua-le yi-zhang $\operatorname{lian}_{9 j / k}$ de sumiao. Zhangsan give Lisi draw-ASP one-CLF face DE sketch 'Zhangsan ${ }_{\mathrm{j}}$ drew Lisi $\mathrm{k}_{\mathrm{k}}$ a sketch of his ${ }_{?_{\mathrm{j} / \mathrm{k}}}$ face.'

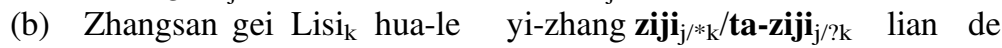
Zhangsan giveLisi draw-ASP one-CLF self/him-self face DE sumiao.

sketch

'Zhangsan ${ }_{\mathrm{j}}$ drew Lisi $\mathrm{k}_{\mathrm{k}}$ a sketch of $\mathrm{his}_{\mathrm{j} / *_{\mathrm{k}}} / \mathrm{his}_{\mathrm{j} / \text { /k }}$ face.'

\subsubsection{Blocking effects}

Further evidence for the contrast between BPNs and KNs regarding their local vs. longdistance binding, respectively, comes from a comparison of BPNs and KNs in their syntactic behavior regarding blocking effects, another well-known syntactic property of long-distance reflexives (Huang \& Tang 1991, Xue et al. 1994, Pan 2001).

It has long been noticed that first- and second-person pronouns can block thirdperson NPs from long-distance binding of ziji. (24a) reveals that in general, any c-commanding third person nouns can be the antecedent of ziji. However, in (24b), although Yuehan 'John', wo 'I', $n i$ 'you', and Tangmu 'Tom' all c-command ziji and are all in principle possible antecedents, only the lowest c-commanding NP, Tangmu can serve as the antecedent. This is because the first- or second-person pronoun prevents the reflexive from taking the first NP Yuehan 'John' as its antecedent (see Charnavel et al. 2017 and references therein for competing explanations of the blocking effect).

(24) (a) Yuehan ${ }_{i}$ renwei Yage zhidao Tangmu $_{k}$ dui $\mathbf{z i j i}_{\mathrm{i} j \mathrm{j} / \mathrm{k}}$ mei John think Jacob know Tom toward self no xinxin. confidence

' $\mathrm{John}_{\mathrm{i}}$ thinks that $\mathrm{Jacob}_{\mathrm{j}}$ knows that $\mathrm{Tom}_{\mathrm{k}}$ is not confident in himself/ $\operatorname{him}_{\mathrm{i} j / \mathrm{k}}$.' 
(b) Yuehan ${ }_{i}$ renwei $\mathbf{w o}_{j} / \mathbf{n i}_{\mathrm{k}}$ zhidao Tangmu $\mathrm{n}_{\mathrm{n}} \mathrm{dui}$ John think I/you know Tom toward self mei xinxin. no confidence

' $\mathrm{John}_{\mathrm{i}}$ thinks that $\mathrm{I}_{\mathrm{j}} / \mathrm{you}_{\mathrm{k}}$ know that $\mathrm{Tom}_{\mathrm{m}}$ is not confident in $\mathrm{him}_{*_{\mathrm{i}}} /$ $\mathrm{me}_{* \mathrm{j}} / \mathrm{you}_{* \mathrm{k}} / \mathrm{himself}_{\mathrm{m}}$.'

Crucially, similar blocking effects are observed with the implicit argument of KNs. For instance, when we replace the simple reflexive ziji with the KN erzi 'son', exactly the same contrast as in $(24 a, b)$ is detected between $(25 a, b)$.
(a) Zhangsan Z $_{\mathrm{i}}$ renwei $[\mathrm{TP}$ Zhangsan think Wangwu $_{\mathrm{j}}$ zhidao ${ }_{\mathrm{TPP}}$ Lisi $_{\mathrm{k}}$ dui $\operatorname{erzi}_{\mathrm{i} / j \mathrm{k}}$ mei xinxin]]. no confidence 'Zhangsan ${ }_{\mathrm{i}}$ thinks that $\mathrm{Wangwu}_{\mathrm{j}}$ knows that $\mathrm{Lisi}_{\mathrm{k}}$ is not confident in his $\mathrm{i}_{\mathrm{i} j \mathrm{k}}$ son.'
(b) Zhangsan ${ }_{i}$ renwei[TP wo $_{\mathrm{j}} / \mathbf{n i}_{\mathrm{k}}$ zhidao [TP $\mathbf{L i s i}_{\mathrm{m}}$ dui $\mathbf{e r z i}_{*_{\mathrm{i}} / *_{\mathrm{j}} / * \mathrm{k} / \mathrm{m}}$ mei xinxin]].

\subsection{Some other contrasts between BPNs and KNs}

We have shown that the implicit arguments of body-part and kinship RNs are different in that the former must be locally bound whereas the latter can be either locally or long-distance bound. In this section, we would like to directly contrast BPNs and KNs in other special circumstances. As in English, a DP with an accessible subject, e.g. a nominalized DP (26) or a relative clause (27), is a binding domain in Chinese, and it will block long-distance binding outside the local binding domain of a BPN as in (26a) and (27a), but not that of a KN as in (26b) and (27b).
(a) Zhangsan ${ }_{\mathrm{j}}$ zanyang-le lDP $_{\mathrm{DP}} \mathrm{Lisi}_{\mathrm{k}}$ jishi baoza shoushang Zhangsan praise-ASP Lisi timely bind.up wound de $\quad$ shoubi $_{? * j / k}$ de xingwei].
DE arm DE behavior

'Zhangsan ${ }_{\mathrm{j}}$ praised Lisi $\mathrm{k}_{\mathrm{k}}$ 's timely binding of $\left(\mathrm{his}_{? \mathrm{P}_{\mathrm{j} / \mathrm{k}}}\right)$ injured arm.'

(b) Zhangsan ${ }_{\mathrm{j}}$ zanyang-le [DP Lisi $\mathrm{K}_{\mathrm{k}}$ jishi baoza shoushang de Zhangsan praise-ASP Lisi timely bind.up wound DE $\operatorname{muqin}_{\text {?jk }}$ de xingwei]. mother DE behavior 'Zhangsan ${ }_{\mathrm{j}}$ praised Lisi $_{\mathrm{k}}$ 's timely binding of (his $\left.{ }_{\mathrm{f}_{\mathrm{j} k \mathrm{k}}}\right)$ injured mother.'

(27) (a) Zhangsan ${ }_{j}$ renshi nage $\left[{ }_{R C}\left[t_{k}\right.\right.$ zheduan-le shoubi $\left.i_{* *_{j} k}\right]$ de xiaohuozi $\left.{ }_{k}\right]$. Zhangsan know that break-ASP arm DE young.man 'Zhangsan ${ }_{\mathrm{j}}$ knew the young $\operatorname{man}_{\mathrm{k}}$ who broke his ${\text { ? }{ }_{\mathrm{j} / \mathrm{k}}}$ arm.' 
(b) Zhangsan ${ }_{j}$ renshi nage $\left[{ }_{R C}\left[t_{k}\right.\right.$ piping-le fuqi $\left.n_{j k}\right]$ de xiaohuozi $\left.i_{k}\right]$. Zhangsan know that criticize-ASP father DE young.man 'Zhangsan ${ }_{j}$ knew the young man $_{k}$ who criticized his $\mathrm{j}_{\mathrm{j} / \mathrm{k}}$ father.'

Finally, reconstruction provides another way to distinguish the implicit argument of BPNs from that of KNs. Similar to English reflexives (Huang 1993, Heycock 1995), we expect the reflexive argument of BPNs and KNs to be subject to reconstruction. This prediction is borne out. We use the lian ... dou 'even ... all' focus construction to front the phrase with KNs or BPNs. As we can see in (28a, b), reconstruction occurs both with the fronted fuqin 'father' and lian 'face' (the elided lower copies are indicated by strikethroughs in the examples), resulting in the interpretation where Lisi binds the fronted $\mathrm{KN}$ and the BPN, although it does not c-command them in the surface form.

(28) (a) Zhangsan ${ }_{j}$ zhidao [CP lian fuqin ${ }_{j / k}$ Lisi $_{k}$ dou hui piping fuqin ${ }_{j / k}$ ]. Zhangsan know even father Lisi all will criticize father 'Zhangsan ${ }_{j}$ knew that Lisi $i_{k}$ would criticize even $\left(\right.$ his $\left._{j_{j k}}\right)$ father.'

(b) Zhangsan ${ }_{j}$ zhidao [CP lian lian ${ }_{* j / k}$ Lisi $_{k}$ dou huapo-le $\operatorname{lian}_{* j / k}$ ]. Zhangsan know even face Lisi all scratch-ASP face 'Zhangsan ${ }_{\mathrm{j}}$ knew that Lisi $\mathrm{k}_{\mathrm{k}}$ scratched even (his $*_{\mathrm{j} / \mathrm{k}}$ ) face.'

However, notice that there is also a clear difference between KNs and BPNs in (28a, b). In (28a), the implicit possessor argument of the KN fuqin 'father' can be bound by Zhangsan, an antecedent outside of the local CP. This is a property of longdistance binding. On the other hand, long-distance binding in this case is not possible with the BPN (28b).

We further notice that if a simple reflexive is inserted as the possessor before the $\mathrm{KN}$ in (28a), as shown in (29a), long-distance binding is still possible. On the other hand, long-distance binding is not available, just like in (28b), if we insert a complex reflexive as the possessor before the BPN (29b).
(a) Zhangsan zhidao $_{\text {CP }}$ lian ziji de fuqin ${ }_{\mathrm{j} / \mathrm{k}}$ Lisi $_{\mathrm{k}}$ dou hui Zhangsan know even self DE father Lisi all will piping ziji de fuqin $\left._{\text {jk }}\right]$. criticize self DE father 'Zhangsan ${ }_{\mathrm{j}}$ knew that $\mathrm{Lisi}_{\mathrm{k}}$ would criticize even $\left(\mathrm{his}_{\mathrm{j} / \mathrm{k}}\right.$ ) father.'
(b) Zhangsan ${ }_{\mathrm{j}}$ zhidao $_{\text {[CP }}$ ta-ziji $_{?_{* j} / \mathrm{k}}$ lian de lian Lisi dou huapo-le Zhangsan zhidao him-self even DE face Lisi all scratch-ASP ta-ziji ${ }_{2} *_{j / k}$ de lian]. him-self DE face
'Zhangsan ${ }_{\mathrm{j}}$ knew that $\mathrm{Lisi}_{\mathrm{k}}$ scratched even his own ${ }_{*_{\mathrm{j} / \mathrm{k}}}$ face.'

In sum, we have shown in this section that in Chinese the implicit argument shows local binding properties in BPNs, akin to the complex reflexive ta-ziji, and longdistance binding properties in KNs, akin to the simple reflexive $z i j i$ 'self'. 


\section{LOgOPHORICITY DISTINCTION OF IMPLICIT ARGUMENTS OF RNS}

A remaining puzzle is why there is such a distinction between BPNs and KNs. That is, why must the implicit argument of BPNs be locally bound, whereas that of KNs can be long-distance bound? In this and the next section, we propose that the binding properties of RN's implicit arguments are related to their logophoricity properties, and consider two tentative accounts for this distinction.

Our proposal is that in Chinese, the implicit argument of KNs, like the simple reflexive ziji, shows logophoric properties, which enables it to refer to a longdistance antecedent. However, the implicit argument of BPNs cannot be a logophor, and its binding is locally restricted. This proposal is compatible with Huang \& Liu (2001), Reuland (2001) and Charnavel \& Sportiche (2016), who argue that longdistance binding is a result of logophoricity. ${ }^{10}$

Logophors, often referred to in the literature as logophoric pronouns, were firstly reported in West African languages (e.g. Ewe) with regard to a type of pronouns that is morphologically distinct from standard pronouns and from reflexives, referring specifically to 'the individual (other than the speaker) whose speech, thoughts, feelings, or general state of consciousness are reported or reflected in the linguistic context in which the pronoun occurs' (Clements 1975: 141). ${ }^{11}$ Sells (1987) further divides logophors into three types: the SOURCE, the SELF and the PIVOT. "The SOURCE is the one who makes the report (for example, the speaker). The SELF represents the one whose 'mind' is being reported; the PIVOT represents the one from whose point of view the report is made." (Sells 1987: 455)

Building on Sells (1987), Huang \& Liu (2001) and Huang et al. (2009) argue that locally bound reflexives are pure or plain anaphoric reflexives which are subject to standard binding theory (Chomsky 1981, 1986), and long-distance bound reflexives are logophors (see also Reuland 2001). ${ }^{12}$ They suggest that long-distance simple reflexive ziji is limited to logophoric uses. In the following we provide several diagnostics for (non-)logophoric reflexives. ${ }^{13}$

[10] A comprehensive review of the competing theories of reflexives in Chinese is beyond the scope of this paper. Interested readers are referred to Charnavel et al. (2017) for a critical evaluation of different proposals and extensive references.

[11] Logophors are claimed to occur in English too. For instance, himself in (ia) and myself in (ib) are not bound locally but refer to the person whose belief or speech is reported.

(i) (a) Tom believed that the paper had been written by Ann and himself.

(b) Physicists like myself were never too happy with the parity principle

[12] Reinhart \& Reuland (1993) hold a stricter constraint that only reflexives in argument positions are subject to their counterpart of Condition A (applying to local anaphors). This excludes all cases where reflexives are in adjunct positions.

[13] Due to space limitation, we do not discuss every diagnostic proposed in the literature, some of which are more controversial. For example, Huang \& Liu (2001) argue that obligatory de se reading is a property of logophoric reflexives. However, Wang \& Pan (2014) and Chen (2018) point out many counterexamples, showing that long-distance reflexives in Chinese are not necessarily interpreted $d e$ se. We thus leave a comprehensive evaluation of the diagnostics of 


\subsection{Blocking effects}

One such diagnostic is blocking effects in reflexive binding. Huang et al. (2009: Chapter 9) consider blocking effects a result of invalid shifts in perspectives. They thus predict that blocking effects occur only with long-distance reflexives, not with locally bound, non-logophoric ziji. This prediction is justified by the contrast in (30).
(a) Yuehan ${ }_{\mathrm{i}}$ renwei $\mathbf{w o}_{\mathrm{j}} / \mathbf{n i}_{\mathrm{k}}$ zhidao Tangmu $_{\mathrm{m}}$ dui $\mathrm{ziji}_{*_{\mathrm{j}} / *_{\mathrm{j}} / *_{\mathrm{k}} / \mathrm{m}}$ John think I/you know Tom toward self mei xinxin. no confidence

' $\mathrm{John}_{\mathrm{i}}$ thinks that $\mathrm{I} / \mathrm{you}$ know that $\mathrm{Tom}_{\mathrm{m}}$ is not confident in himself $\mathrm{*}_{\mathrm{*}_{\mathrm{i}} / \mathrm{m}} /$ *me/*you.'

(b) Zhangsan ${ }_{\mathrm{j}}$ hui gaosu $\quad \mathbf{w o}_{\mathrm{k}} / \mathbf{n i}_{\mathrm{m}} \quad \mathrm{ziji}_{\mathrm{j} / \mathrm{k} / \mathrm{m}}$ de fenshu. Zhangsan will tell me/you self DE grade 'Zhangsan will tell me/you about his/my/your own grade.'

In (30a), the first- and second-person pronouns wo/ni 'I/you' prevent the reflexive from taking the long-distance NP Yuehan 'John' as its antecedent, whereas such blocking effect is absent with the locally bound reflexive in (30b).

In parallel, (31 a) indicates that when the implicit argument of the $\mathrm{KN}$ erzi 'son' is locally bound, it is also not subject to blocking effects, although we have also seen in Section 3.2 that KNs exhibit blocking effects when they are long-distance bound. ${ }^{14}$ Comparatively, as demonstrated by (31b), BPNs, like locally bound reflexives, are also exempt from blocking effects.

(a) Zhangsan $\mathrm{j}_{\mathrm{j}}$ hui gaosu $\mathrm{wo}_{\mathrm{k}} / \mathrm{ni}_{\mathrm{m}}$ erzi $\mathrm{i}_{\mathrm{j} / \text { ? } \mathrm{k} / ? * \mathrm{~m}}$ de fenshu. Zhangsan will tell I/you son DE grade 'Zhangsan will tell me/you about his/?*my/?*your son's grade.'

(b) Zhangsan ${ }_{\mathrm{j}}$ hui gaosu $\mathrm{wo}_{\mathrm{k}} / \mathrm{ni}_{\mathrm{m}}$ shoubi $\mathbf{j}_{\mathrm{j} / \mathrm{k} / \mathrm{m}}$ de shoushang qingkuang. Zhangsan will tell $\mathrm{I} / \mathrm{you}$ arm DE injure condition 'Zhangsan will told me/you about his/my/your arm injury.'

\subsection{Sub-command effects}

Sub-command effects, another diagnostic of logophoric use, reveal another disassociation between BPN non-logophors and KN logophors. Sub-command effects are a typical syntactic property of both the simple and complex reflexive in Chinese. Take

logophoricity to future studies. Readers are referred to Charnavel (2017) for a longer list of diagnostics proposed in previous studies.

[14] However, given its subject-orientation requirement, as we saw before, the implicit possessor of erzi 'son' cannot refer to the first- and second-person pronouns in (31a). 
(32) as an example, in which Zhangsan sub-commands the reflexives because it is at the specifier of a possessive phrase that c-commands the reflexive. Although Zhangsan does not c-command the reflexive, the sub-command relation suffices for it to be the antecedent of the reflexives because the possessee (jiao'ao 'pride') is inanimate. ${ }^{15}$

$$
\begin{aligned}
& \text { [ Zhangsan }{ }_{j} \text { de jiao'ao] hai-le ziji } / \text { ta-ziji }_{j} \text {. } \\
& \text { Zhangsan DE pride hurt-AsP self/him-self } \\
& \text { '[Zhangsan }{ }_{j} \text { 's arrogance] harmed him }{ }_{j} \text {.' }
\end{aligned}
$$

Charnavel \& Huang's (2018) grammaticality judgment experiments indicate a correlation between sub-command effects and logophoricity. In addition, inanimate anaphors (anaphors that are bound by inanimate antecedents), which lack a mental state, are incompatible with logophoricity (see also Charnavel \& Sportiche 2016). Charnavel \& Huang (2018: 140) find that inanimate anaphors also do not exhibit subcommand effects (33), confirming that sub-command effects are an artifact of logophoricity.

$$
\begin{aligned}
& *\left[[\text { Zhe ke shu }]_{\mathrm{j}} \text { de guoshi] ya wan-le ziji } \mathrm{j}_{\text {. }}\right. \\
& \text { this CL tree DE fruit press bent-ASP self } \\
& \text { '[The fruits of [this tree } \left.]_{\mathrm{j}}\right] \text { bent itself } \mathrm{j}_{\mathrm{j}} \text {. }
\end{aligned}
$$

Below we present two additional pieces of evidence to support the argument that sub-command is an artifact of logophoricity.

We notice further that, unlike regular bound reflexives, sub-commanded reflexives cannot be reconstructed. For example, we focalize the sub-commanded reflexive in (32) over its antecedent, as in (34).

$$
\begin{aligned}
& \text { ?*Lian ziji } / \text { ta-ziji }_{\mathrm{j}} \text { Zhangsan }_{\mathrm{j}} \text { de jiao'ao dou hai-le. } \\
& \text { even self/him-self Zhangsan DE pride all hurt-ASP } \\
& \text { Intended: '[Zhangsan }{ }_{\mathrm{j}} \text { 's arrogance] even harmed him }{ }_{\mathrm{j}} \text {.' }
\end{aligned}
$$

In this case, the reflexive cannot be reconstructed to its original position and be bound by the antecedent, although we showed in Section 3.3 that regularly bound reflexives do exhibit reconstruction effects in the same context. The absence of reconstruction effects further underpins Charnavel \& Huang's (2018) argument that sub-command effects are not regular binding and they signal logophoric uses.

[15] In fact, sub-command is also blocked when the possessee is inanimate but a plausible antecedent of the reflexive, illustrated in (i), which suggests that sub-command is only available when the regular binding relation built on c-command cannot be established.

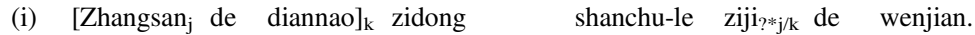
Zhangsan DE computer automatically delete-ASP self DE document 'Zhangsan's computer automatically deleted ?*his/its documents.'

If sub-command is a logophoric property, then this restriction would follow from Reuland's (2001) claim that the logophoric use can be blocked when a regular local binder is possible. 
In parallel, we also observe that KNs exhibit sub-command effects but BPNs do not, as illustrated in (35) and (36b), respectively.
(a)
[ Zhangsan ${ }_{j}$ de jiao'ao] hai-le fuqin . $_{\text {. }}$ Zhangsan DE pride hurt-AsP father
'[Zhangsan ${ }_{\mathrm{j}}$ 's arrogance] harmed his $\mathrm{j}_{\mathrm{j}}$ father.'
(b) $\left[\right.$ Zhangsan $_{\mathrm{j}}$ de shouji $]$ zadao-le didi . $_{j}$.
Zhangsan DE cell.phone hit-ASP younger.brother
'[Zhangsan ${ }_{j}$ 's cell-phone] hit his ${ }_{j}$ younger brother.'
(a) $\left[\right.$ Zhangsan $_{j}$ de shouji $]$ zadao-le jiao ${ }_{?} * \mathrm{j} / \mathrm{ARB}$.
Zhangsan DE cell.phone hit-AsP foot

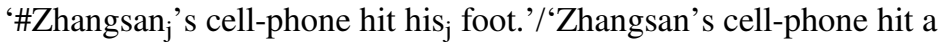 foot.'

(b) [ Zhangsan $_{\mathrm{j}}$ de shoubiao] gua-shang-le shouzhi $_{* \mathrm{j} / \mathrm{ARB}}$. Zhangsan DE watch scratch-injured-AsP finger

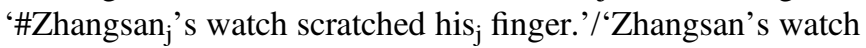
scratched a finger.'

The main difficulty our consultants have with $(36 a, b)$ is that they were not clear about who the possessors of the BPNs are. However, if an overt pronoun possessor is inserted right before the BPN, these two examples become perfectly acceptable. Therefore, KNs are compatible with logophoricity regarding the sub-command possibility, but BPNs are not.

Notice that a subset of native speakers reported that they accepted both $(36 a, b)$. However, the majority of these speakers got an arbitrary interpretation of the BPNs in (36), but not for the KNs in (35). That is, jiao 'foot' and shouzhi 'finger' in (36) can be a foot or a finger of someone other than Zhangsan; however, fuqin 'father' and didi 'younger brother' in (35) can only be Zhangsan's father or younger brother. With the arbitrary interpretation, the BPNs can be any person's body parts (including Zhangsan's). Further evidence for the arbitrary interpretation of BPNs in (36) comes from (37).
(a) ?*Lian didi $_{\mathrm{k}} \quad$ Zhangsan $_{\mathrm{j}}$ de shouji dou zadao-le. even younger.brother Zhangsan DE cell.phone all hit-ASP Intended: 'Zhangsan's cell phone hit even his younger brother.'
(b) Lian jiao Zhangsan de shouji dou zadao-le. even foot Zhangsan DE cell.phone all hit-ASP 'Zhangsan's cell phone hit even his (or someone else's) foot.'

All speakers we consulted found a distinction between these two reconstruction sentences. It is expected that (37a) is not acceptable, as we have seen in (34) that sub-command generally cannot be reconstructed. Consequently, our consultants complained that the reference of didi 'younger brother' was unclear, and they would like to add a pronominal possessor before it if it meant to refer to Zhangsan's brother. Why then is (37b) good? Consistent with our explanation of (36), we suggest that 
this is because jiao 'foot' is interpreted as a non- $\mathrm{RN}$, receiving an arbitrary interpretation, although pragmatically Zhangsan is a more salient possessor. In the case of this arbitrary interpretation, the implicit argument of the BPN is arguably suppressed (Barker 1995) or saturated (Zhang 2009) (see also footnote 6 above), thus not requiring to be bound by an antecedent.

\subsection{VP ellipsis}

VP ellipsis is another test that can help us tease apart logophoric and anaphoric properties. Reuland (2001) proposes that logophoric use is a kind of pronominal use (see also Bouchard 1982: 78; Cole, Hermon \& Huang 2001: xvii). Anaphoric and logophoric reflexives are therefore predicted to be in complementary distribution, because the logophoric use is blocked in instances in which the anaphor can be locally bound. Huang \& Liu (2001) apply this hypothesis to Chinese and suggest that longdistance reflexives in Chinese are logophors, different from locally bound reflexives. If this hypothesis is on track, we expect that long-distance reflexives should share certain properties with pronouns that are not observed with locally-bound anaphors. In support of this connection, we will show below that Chinese long-distance reflexives elided inside a VP will result in a strict reading in addition to a sloppy reading, a property shared with pronouns, contrary to what has been assumed in some previous studies (e.g. Cole et al. 2001, Huang \& Liu 2001, Charnavel et al. 2017).

In Section 3, we pointed out that VP ellipsis of locally bound reflexives allows the sloppy reading but not the strict reading, whereas VP ellipsis of pronouns allows either reading. It is therefore reasonable to anticipate that long-distance bound reflexives under VP ellipsis, like pronouns, lead to either the strict or the sloppy readings. However, Cole et al. (2001) and Huang \& Liu (2001) suggest that this prediction is incorrect, and argue that logophoric reflexives do not give rise to a strict reading. Their examples in $(38 \mathrm{a}, \mathrm{b})$ show that only the sloppy reading is available for both sentences. The corresponding sloppy readings are in (39a, b), respectively.

(a) Zhangsan ${ }_{\mathrm{i}}$ shuo Lisi changchang kuidai $\mathrm{ziji}_{\mathrm{i}}$, Wangwu ye Zhangsan say Lisi always mistreat self Wangwu also yiyang.

the.same

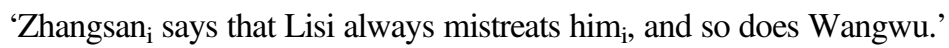

(Cole et al. 2001: 28)

(b) Zhangsan juede Lisi chang qipian ziji, Wangwu ye shi. Zhangsan feel Lisi often cheat self Wangwu also be 'Zhangsan feels that Lisi often cheated him, and so does Wangwu.'

(Huang \& Liu 2001: 42)

(39) (a) Wangwu $\mathrm{K}_{\mathrm{k}}$ also says that Lisi always mistreats him . $_{\mathrm{k}}$ (sloppy reading)

(b) $\mathrm{Wangwu}_{\mathrm{k}}$ also feels that Lisi often cheated him $\mathrm{k}_{\mathrm{k}}$ (sloppy reading)

This is quite surprising, as it has been shown that long-distance reflexives lead to both strict and sloppy readings under VP ellipsis, in languages such as English 
(Lebeaux 1985, Hicks 2009), as illustrated in (40a), where the possible interpretations of pictures of himself in the elided VP are listed following the sentence. By contrast, locally bound reflexives in English exhibit only the sloppy reading (40b).

(40) (a) John thought there were some pictures of himself for sale on eBay, and Bill did too.

$=$ pictures of John, or:

$=$ pictures of Bill

(strict reading)

(b) John respects himself, and Bill does too.

$=$ respects Bill, but:

$!=$ respects John

(sloppy reading)

(sloppy reading)

(strict reading)

(Hicks 2009: 137)

It is an open question as to why the sloppy reading is the dominant reading, if not the only reading, for the elided reflexives in $(38 \mathrm{a}, \mathrm{b})$, but we argue that the unavailability of the strict reading in such cases should not be sufficient to rule out the idea that logophoric reflexives share properties with pronouns. It seems the strict reading is dispreferred in such examples due to independent reasons that remain unclear to us. In fact, if we replace the reflexive with a pronoun and keep everything else unchanged, the sloppy reading is still the dominant reading. Take (38a) as an example. If the reflexive is substituted by a pronoun, as in (41), the dominant reading for the elided VP is still the sloppy reading in (39b). ${ }^{16}$

Zhangsan juede Lisi chang qipian ta, Wangwu ye shi.
Zhangsan feel Lisi often cheat he Wangwu also be
'Zhangsan feels that Lisi often cheated him, and so does Wangwu.'

This suggests that the long-distance bound reflexive could still have pronoun properties, since the sloppy reading is still the dominant reading (or the only one accessible for a subset of speakers) even when a pronoun ta 'him' is used in these specific contexts.

Crucially, we would like to further point out that a confounding factor has obscured the test: Cole et al. (2001) and Huang \& Liu (2001) do not distinguish matrix and embedded VP ellipsis in the cases they considered. Take (38a) again. Either the matrix VP (42a) or the embedded VP (42b) can be potentially elided. This confounding factor might have concealed some interpretations of the sentences. ${ }^{17}$

(42) (a) Wangwu also [says that Lisi always mistreats ziji]. (matrix VP ellipsis)

(b) Wangwu also [always mistreats ziji]. (embedded VP ellipsis)

[16] Cole et al. (2001: 28) consider VP ellipsis in sentences such as (41) ambiguous between a strict and a sloppy reading. While we agree that the strict reading is available for some speakers, there does seem to be a strong preference for the sloppy reading.

[17] Notice that similar tests in English can avoid such an ambiguity problem. A test sentence such as (40a) does not have the same problem, for the embedded and the matrix clause use morphologically distinct predicates (an intentional verb versus a copula), so did too elicits matrix VP ellipsis only (targeting the intentional verb). 
Indeed, we found that matrix and embedded VP ellipses lead to different interpretations. For the embedded VP ellipsis, we utilize ye/que shi 'also/yet is' to elicit VP ellipsis (Xu 2003, Soh 2007, Wei 2009, Li \& Wei 2014), like Cole et al. (2001) and Huang \& Liu (2001), but now unambiguously targeting the embedded VP. As exemplified in (43), when the reflexive ziji is locally bound by Zhangsan, only the sloppy reading (44a) is possible.

(43) Lin Jiaoshou $\mathrm{j}_{\mathrm{j}}$ renwei Zhangsan $\mathrm{K}_{\mathrm{k}}$ chang piping $\mathrm{ziji}_{\mathrm{j} / \mathrm{k}} / \mathrm{ta}_{\mathrm{j}}$,

Lin Professor think Zhangsan often criticize self/him

Wangwu renwei Lisi ye shi.

Wangwu think Lisi also be

'Prof. Lin thought Zhangsan often criticized himself, and Wangwu thought Lisi did so, too.'

(44) (a) Wangwu thought Lisi also often criticized himself.

(b) \#Wangwu thought Lisi also often criticized Zhangsan.

(local binding: sloppy reading)

(local binding: strict reading)

This is an example of VP ellipsis with a locally bound reflexive which leads to the sloppy reading but not the strict reading, as expected. Since what we are interested in are actually long-distance bound reflexives, we will ignore the locally bound reading in what follows. However, when the reflexive is long-distance bound by Lin Jiaoshou 'Prof. Lin' in (43), both the strict (45b) and the sloppy readings (45a) are available; to some speakers, the strict reading is actually preferred.

(45) (a) Wangwu $\mathrm{j}_{\mathrm{j}}$ thought Lisi also often criticized him $\mathrm{j}_{\mathrm{j}}$. (long-distance binding: sloppy reading)

(b) Wangwu thought Lisi also often criticized Prof. Lin.

(long-distance binding: strict reading)

If we replace the reflexive with a pronoun, as indicated in (43), in accordance with our expectation, we can access either the sloppy or the strict reading in (45), similar to the long-distance bound reflexive.

A test using focused negation yi-dian ye bu 'not at all' (see Hsieh 2001 and Soh 2007) arrives at the same conclusion:

$\begin{array}{llllll}\text { Zhangsan }_{\mathrm{k}} & \text { renwei } & \text { Mali } & \text { hen } & \text { xihuan } & \mathrm{ziji}_{\mathrm{k}} / \mathrm{ta}_{\mathrm{k}} \text {, } \\ \text { Zhangsan } & \text { think } & \text { Mary } & \text { very } & \text { like } & \text { self/him } \\ \text { Lisi } & \text { renwei } & \text { Mali } & \text { yi-dian } & \text { ye } & \text { bu. } \\ \text { Lisi } & \text { think } & \text { Mary } & \text { one-bit } & \text { also } & \text { not }\end{array}$

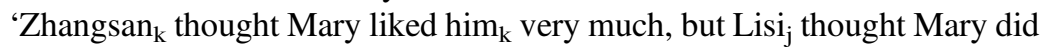
not like $\operatorname{him}_{\mathrm{k} / \text { ??j }}$ at all.'

The use of the focused negation requires a contrastive context, and this requirement leads to a strong preference for the strict reading in (46). 
For matrix VP ellipsis, since Chinese does not have a verbal pro-form equivalent to do in English as in do so, we use constructions with modals (e.g. hui 'will') as the licenser targeting matrix VP ellipsis (see Xu 2003, Li \& Wei 2014). The reflexives contained in the elided VP in (47) have the sloppy reading (48b) as their dominant reading, corresponding to the sloppy reading observed in (38) by Cole et al. (2001) and Huang \& Liu (2001). In such cases the strict reading (48a) is either dispreferred or inaccessible to speakers.

$\begin{array}{lllllll}\text { Zhangsan } & \text { hui } & \text { juede Lin Jiaoshou guyi } & \text { weinan ziji, } \\ \text { Zhangsan } & \text { will feel Lin Professor intentionally embarrass self } & \\ \text { Lisi } & \text { ye hui. } & & & & \\ \text { Lisi } & \text { also will } & & & \end{array}$

'Zhangsan will feel that Prof. Lin intentionally embarrassed him, and Lisi will too.' 18

(48) (a) Lisi will also feel that Prof. Lin intentionally embarrassed Zhangsan.

(b) Lisi $\mathrm{j}_{\mathrm{j}}$ will also feel that Prof. Lin intentionally embarrassed him $_{\mathrm{j}}$. (strict reading)

(sloppy reading)

However, even if we consider that the strict reading is inaccessible in (47), it does not follow that long-distance bound reflexives lack pronoun properties, because if we replace the reflexive with a pronoun (49), the dominant interpretation is still the sloppy reading (48b).

(49) Zhangsan hui juede Lin Jiaoshou guyi weinan ta, Zhangsan will feel Lin Professor intentionally embarrass him

Lisi ye hui.

Lisi also will

'Zhangsan will feel that Prof. Lin intentionally embarrassed him, and Lisi will too.'

[18] Previous studies also use the construction zheme 'such' + verb to elicit matrix VP ellipsis (see Huang 1991: 63-66 for Mandarin and Kim \& Yoon 2009: 742-743 for Korean), where the verb repeats the matrix verb from the antecedent sentence. The example in (i) shows that, with this test, the strict reading is strongly preferred to the sloppy reading, as seen in (iia) vs. (iib). This represents a clearer case in which the strict reading is more prominent than that with the modal hui 'will'. However, there may be a concern that zheme 'such' + verb could be an instance of argument ellipsis, which would make the results of this test irrelevant as a test of VP ellipsis.

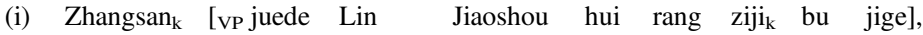 Zhangsan feel Lin Professor will let self not pass Wangwu ye [zheme juede]. Wangwu also such feel 'Zhangsan ${ }_{k}$ feels that Prof. Lin will not let him ${ }_{k}$ pass the exam, and Wangwu also feels that way (Prof. Lin will not let him [ziji] pass the exam).'

(ii) (a) Wangwu feels that Prof. Lin will not let Zhangsan pass the exam.

(b) ??Wangwu $\mathrm{k}_{\mathrm{k}}$ feels that Prof. Lin will not let him $\mathrm{k}_{\mathrm{k}}$ pass the exam.

(strict reading) (sloppy reading) 
Furthermore, in a proper context, the strict reading for (47) becomes more prominent. Sentences such as (47), copied below as (51), are more natural with contexts asserting the antecedent of the conditional, because they usually describe the consequent of certain conditional statements. If we now add such a context that favors the strict reading, as in (50), both a reflexive as (51) and a pronoun (53) in the elided VPs can lead to the strict reading in (52) (identical to (48a)).

(50) Context: Zhangsan got a bad score in Prof. Lin's class. If Prof. Lin announces Zhangsan's grade in front of the class,

$\begin{array}{llllll}\text { Zhangsan hui juede Lin Jiaoshou guyi } & \text { weinan ziji, } \\ \text { Zhangsan } & \text { will feel Lin Professor intentionally embarrass self } \\ \text { Lisi } & \text { ye hui. } & & & \\ \text { Lisi } & \text { also will } & & \end{array}$

'Zhangsan will feel that Prof. Lin intentionally embarrassed him, and Lisi will too.'

(52) Lisi will also feel that Prof. Lin intentionally embarrassed Zhangsan.

(strict reading $)^{19}$

$\begin{array}{lllllll}\text { Zhangsan } & \text { hui } & \text { juede } & \text { Lin Jiaoshou guyi } & \text { weinan ta, } \\ \text { Zhangsan } & \text { will } & \text { feel Lin Professor intentionally embarrass him } \\ \text { Lisi } & \text { ye hui. } & & & & \\ \text { Lisi } & \text { also will } & & & \end{array}$

'Zhangsan will feel that Prof. Lin intentionally embarrassed him, and Lisi will too.'

A summary of the results of the VP ellipsis test is provided in Table 1. In sum, when the embedded VP is elided, the strict reading is the primary interpretation, although the sloppy reading is also available, especially under appropriate contexts; however, when the matrix VP is elided, both readings are available, and to some speakers the strict reading is preferred. The ambiguity in both cases would be compatible with VP ellipsis properties of a pronoun argued for logophors. Although the cause of these preferences remains unclear, the results are consistent with the hypothesis that locally bound reflexives are 'plain' anaphors, whereas long-distance (LD in Table 1) reflexives, as logophors, share properties with pronouns.

After addressing the relevant issues concerning the use of VP ellipsis as a test for logophors in Chinese, let us return to the distinction between locally bound and long-distance bound implicit arguments of KNs. ${ }^{20}$ If our analysis so far is on the

[19] Some speakers we tested reported that although they can accept (51) under the context in (50), the sentences would be better if zheme juede 'so feel' was added to the end, with a structure similar to what we used in Footnote 17. We believe that this is because the preferred reading of (51) without the context (50) is the sloppy reading, which is incompatible with the context. However, adding zheme juede 'so feel' will switch the preference to the strict reading, which is perfectly consistent with the context.

[20] The VP ellipsis tests that target long-distance bound reflexives are not applicable to BPN implicit arguments, since the latter must be locally bound. 


\begin{tabular}{|c|c|c|c|c|c|c|c|}
\hline \multicolumn{4}{|c|}{ Embedded VP ellipsis } & \multicolumn{4}{|c|}{ Matrix VP ellipsis } \\
\hline \multicolumn{2}{|c|}{ Pronoun } & \multicolumn{2}{|c|}{ Reflexive } & \multicolumn{2}{|r|}{ Pronoun } & \multicolumn{2}{|r|}{ Reflexive } \\
\hline Local & LD & Local & LD & Local & LD & Local & LD \\
\hline
\end{tabular}

Table 1

Interpretations of the elided reflexives and pronouns in matrix and embedded VP ellipsis. Corresponding examples' numbers are provided in parentheses; LD = long distance. 
right track, additional tests should set the two types of RNs apart by relating the long-distance bound implicit argument of KNs to logophors and the locally bound implicit argument of KNs (as well as that of BPNs) to locally bound reflexives. For KNs, we find exactly the same interpretations in the four cases of VP ellipsis we examined for the simple reflexive. (54) is an example where the matrix VP is elided.

$$
\begin{array}{llll}
\text { Zhangsan }_{\mathrm{j}} & \text { renwei } & \text { Lin } \text { Jiaoshou }_{\mathrm{k}} \text { hen zunjing fuqin } \\
\mathrm{j} & \\
\text { Zhangsan think } & \text { Lin Professor very respect father, } \\
\text { Lisi } & \text { ye } & \text { zheme renwei. } \\
\text { Lisi } & \text { also such think } \\
\text { 'Zhangsan } &
\end{array}
$$

As in the case of reflexives, we should put aside the irrelevant case where the KN, fuqin 'father', is locally bound by Lin Jiaoshou 'Professor Lin'. When the KN implicit argument is long-distance bound by Zhangsan, the dominant reading is the strict reading (55a), and the sloppy reading (55b) is difficult, if not impossible, to obtain.

(55) (a) Lisi also thinks that Prof. Lin respects Zhangsan's father. (strict reading)

(b) ??Lisi $\mathrm{i}_{\mathrm{i}}$ also thinks that Prof. Lin respects his ${ }_{\mathrm{i}}$ father. (sloppy reading)

As we observed for reflexives, if we use the auxiliary $h u i$ 'will' to induce VP ellipsis (56), then the opposite result occurs: the sloppy reading is preferred, and the strict reading is degraded. Substituting the $\mathrm{KN}$ with a pronoun does not change this preference.

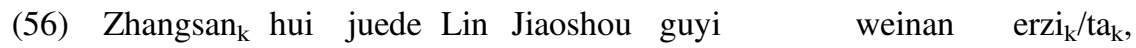
Zhangsan will feel Lin Professor intentionally embarrass son/he $\mathrm{k}_{\mathrm{k}}$

Wangwu ye hui.

Wangwu also will

'Zhangsan ${ }_{\mathrm{k}}$ will feel that Prof. Lin intentionally embarrasses his ${ }_{\mathrm{k}}$ son/him $\mathrm{k}$, and Wangwu also will.'

(57) (a) Wangwu will feel that Prof. Lin intentionally embarrassed Zhangsan ('s son).

(strict reading)

(b) Wangwu will feel that Prof. Lin intentionally embarrassed Wangwu ('s son).

(sloppy reading)

With the embedded VP ellipsis constructions, as in (58), if the implicit argument of the $\mathrm{KN}$ in the antecedent is locally bound by Lin Jiaoshou 'Prof. Lin', the only accessible interpretation is the sloppy reading in (59b); the strict reading (59a) is not possible. 
(58)

$\begin{array}{lllllll}\text { Zhangsan }_{\mathrm{j}} & \text { renwei } & \text { Lin } & \text { Jiaoshou }_{\mathrm{k}} & \text { hen } & \text { zunjing } & \text { fuqin }_{\mathrm{j} / \mathrm{k}} \text {, } \\ \text { Zhangsan } & \text { think } & \text { Lin } & \text { Professor } & \text { very } & \text { respect } & \text { father, } \\ \text { Lisi } & \text { renwei } & \text { Wang } & \text { Jiaoshou } & \text { ye } & \text { shi. } & \\ \text { Lisi } & \text { think } & \text { Wang } & \text { Professor } & \text { also } & \text { be } & \end{array}$
Prof. Wang does so, too.'

(a) *Lisi thinks that Prof. Wang also respects Prof. Lin's father.

(b) Lisi thinks that Prof. Wang $\mathrm{i}_{\mathrm{i}}$ also respects his $\mathrm{s}_{\mathrm{i}}$ father. (local: strict reading)

(local: sloppy reading)

(60) (a) Lisi thinks that Prof. Wang also respects Zhangsan's father. (long-distance: strict reading)

(b) Lisi $_{\mathrm{i}}$ thinks that Prof. Wang also respects his $\mathrm{s}_{\mathrm{i}}$ father.

(long-distance: sloppy reading)

But if the KN implicit argument is long-distance bound by Zhangsan, both readings are possible; to some speakers the strict reading (60a) is actually dominant, and the sloppy reading (60b) is degraded, showing that the elided long-distance bound $\mathrm{KN}$ leads to both the strict and the sloppy reading, behaving like a pronoun.

The contrast between locally bound and long-distance bound implicit possessors of KNs, on a par with the contrast we observed between locally and long-distance bound reflexives, reinforces other results in this paper: (i) the implicit argument of KNs bears syntactic properties that are similar to the simple reflexive in Chinese; (ii) reflexives and the implicit possessor arguments of KNs that are long-distance bound are different from their locally bound counterparts in that the former are logophors and share properties with pronouns under VP ellipsis.

In sum, both the implicit argument of BPNs and that of KNs can be locally bound anaphors, but these two types of implicit argument differ in that, when local binding does not take place, the latter can be a logophor, but the former cannot. ${ }^{21}$

The null arguments of BPNs and KNs thus correspond to the locally bound reflexive ta-ziji 'herself/himself/itself' and the long-distance reflexive ziji 'self' in Chinese in terms of their interpretations, respectively. Note that the null argument of BPNs can be replaced by an overt non-locally bound reflexive (as in ziji de shou 'self's hand') or a referential DP, and the null argument of KNs can be replaced by an overt non-long-

[21] One may argue that at least the BPN cases we are dealing with could alternatively represent a control PRO. We have a possible answer to that criticism: our results show that there are in fact two types of implicit arguments (in BPNs and KNs), undermining the proposal of a unified control PRO approach to them, especially considering that there is no precise counterpart in the typology of PRO to the distinction we observe here between local binding and long-distance/ logophoric binding for BPNs and KNs. In addition, a theoretical approach that dispenses with different types of PRO in different domains of the grammar is more satisfactory from a minimalist perspective (see e.g. Hornstein 2003, Pires 2006). 
distance bound reflexive (as in ta-ziji de fuqin 'his own father') or a referential DP. ${ }^{22}$ However, if the arguments are null, the bare RNs will end up getting the 'default' interpretations: for BPNs, the null argument will be interpreted as a locally bound reflexive, and for KNs, long-distance reflexive. ${ }^{23}$ The reader may wonder where these default interpretations are originated from. In the next section, we will briefly discuss three reasons that might have caused the distinctive default interpretations of BPNs and KNs.

\section{Why ARE BPNS AND KNS DIFFERENT?}

If we are on track regarding the differences between the binding and logophoric properties of bare BPNs and KNs, a relevant question is what is the source of such differences? Whereas the exact answer is not completely clear to us, we would like to point out some clues that may shed light on this question.

Three conceptual and empirical conjectures may be suggestive regarding why implicit possessors of BPNs (or body-part reflexives) are generally locally bound and not compatible with logophoricity, unlike KNs. First, a lexical difference between BPNs and KNs is that BPNs as arguments do not in fact introduce an additional participant to the event represented by the predicate (see Fox 1981:331-335; Reuland 2011: 228-245). For instance, John hurt his arm entails John hurt himself. This results in a sort of referential overlap between the external and internal arguments. Nevertheless, sentences with KNs, for example John hurt his mother, do not have such an entailment but instead involve an additional participant besides John, John's mother, in the event. If (partial) identity between the corresponding arguments (or between the theta-roles) leads to the reflexive marking of the predicate, as argued by Reinhart \& Reuland (1993), then the source of the local binding of implicit arguments of BPNs can be explained. Possibly related evidence from Lardil indicates that BPNs do reflexively mark the predicate, as shown in (62), where a reflexive morpheme is added to the verb when its object is a BPN (Klokeid 1976: 290-291; Fox 1981: 332).
(a) Ngata I
'I'll wash myself.'
(b) Ngata yuud padkine.e nguda. I PFV bump.REFL forehead.NOM 'I bumped my forehead.'

[22] Following Ke et al. (2019), we suggest that the overt possessor of RNs is originally projected as the internal argument of RNs and then raises to the possessor position of the NP headed by the RNs.

[23] A similar case is found with ECM verbs: if the specifier of the embedded TP in (ia) is filled by a referential DP, i.e. Bill, there is no need to postulate a PRO; however, when the specifier is null, as in (ib), the null subject obtains a 'default' interpretation (whatever the reason is), that is, as a PRO that obligatorily co-indexes with John.

(i) (a) John wanted [TP Bill to win].

(b) John wanted [TP PRO to win]. 
Similarly, in German, a reflexive morpheme can be optionally added when the direct object is a BPN, exemplified in (63) (Fox 1981: 332).

$\begin{array}{lll}\text { Er schüttelte } & \text { (sich) den } & \text { Kopf. } \\ \text { he nodded } & \text { himself the.ACC } & \text { head }\end{array}$

'He nodded his head.'

This may explain why BPNs are typologically the most common lexical origin of reflexives across languages (Schladt 2000). For example, the BPN buru 'head' in Basque is also used as a reflexive. Interestingly, reflexives that are developed from BPNs, usually named body-part reflexives, are generally also locally bound. Based on their corpus study of African body-part reflexives, Reuland \& Schadler (2010: 1) make the following generalization: body-part reflexives must be locally bound in canonical argument positions. Reuland \& Schadler indicate that they found no evidence for body-part reflexives being long-distance bound and/or used as logophors. Whether this generalization is extensible to Chinese needs further research, but it is reasonable at this stage to say that bodypart reflexives in Chinese are more like locally bound reflexives. ${ }^{24}$ In Chinese, we have $z i$-shen 'self-body' as a complex reflexive developed from the BPN shen 'body', and it must be locally bound when it is in canonical object positions, as in (61), unlike ziji (although there are also uses of zishen as an intensifier or a logophor under some restricted cases, see Pan 1995: Chapter 7 and Yu 1996: Chapter 8).
Zhangsan $_{\mathrm{j}}$ renwei
Lisi $_{\mathrm{k}}$ yinggai
fajue $\quad$ zishen $_{* j / k}$
de qianneng.
Zhangsan think
Lisi should
explore self.body
DE potential
'Zhangsan thought Lisi should explore his own potential.'

Another conjecture is that BPNs require physical contexts and for this reason are not compatible with logophoricity licensing predicates such as admire, talked about, as pointed out by Lødrup $(1999,2014)$ in his analysis of Norwegian BPNs, whereas KNs do not have such a restriction. According to Bresnan et al. (2016: 282), a physical context is where 'a possessor acts on or in relation to her body, or locates something in relation to her body, or where someone acts on the possessor by acting on her body.' Similar restrictions are also found for body-part RNs in French (Guéron 2003, 2006). We notice such a restriction is also observed with regard to the relational interpretation of bare BPNs in Chinese. The relational

[24] Xu Shen in Shuowen Jiezi points out that $z i$ (as that in ziji 'self') originally means nose (we should thank Bizhi Guo for bringing this to our attention). Therefore, $z i$ is a body-part reflexive. We predict that $z i$, different from $z i j i$, must be locally bound. Intriguingly, this striking contrast between $z i$ and $z i j i$ is observed in Chinese. For example, historically zi can be used as a standalone reflexive, and it has been confirmed that $z i$ must be locally bound (Cheng 1999, Dong 2002). Ziji can be long-distance bound mainly due to the syntactic contribution of the $j i$ part: $j i$ is a pronominal that is normally long-distance bound (ibid.) 
interpretation becomes inaccessible if the predicates describe abstract thoughts, such as believe, understand, know, study, admire, discuss. There thus seems to be an inherent conflict cross-linguistically between these 'abstract' predicates and bare relational BPNs. However, no such conflict occurs between the same type of predicates and KNs. (64a) instantiates this conflict:

$\begin{array}{ll}\text { (a) } \text { Zhangsan }_{\mathrm{j}} & \text { lijie/yanjiu/renshi/xiangxin/zanshang } \\ \text { Zhangsan } & \text { understand/study/know/believe/admire } \\ \text { de } & \text { zuoyond } \\ \text { DE } & \text { function }\end{array}$

'Zhangsan understood/studied/knew/believed the function of the hand.'

(b) Zhangsan ${ }_{j}$ lijie/yanjiu/renshi/xiangxin/zanshang fuqin ${ }_{j}$

Zhangsan understand/study/know/believe/admire father

de zuoyong.

DE function

'Zhangsan understood/studied/knew/believed the function of his father.'

Given an abstract predicate, shou 'hand' does not carry an implicit relational interpretation, suggesting that the locally bound implicit possessor does not get realized syntactically in such cases. The only interpretation that is available here is the arbitrary interpretation. On the other hand, KNs such as fuqin 'father' can still be relational in the same contexts $(64 b)$.

These predicates describing thoughts or states of mind are usually licensers for logophoric use (Charnavel \& Zlogar 2015, Rudnev 2017). For example, Rudnev (2017) finds a simple reflexive in Avar, $z i w$, which is only allowed to be longdistance bound, and argues that it must be a logophor because the matrix predicate must be 'a verb of saying, belief, or perception' (attitudinal predicate) to license the logophor in the embedded clause (Rudnev 2017: 165-166).

Note that the inaccessibility of the relational interpretation of the BPN in (64a) is not because these abstract predicates are themselves not compatible with objects that include body-part RNs. In (65), where a complex reflexive possessor of the $\mathrm{BPN}$ is inserted, the relational meaning of the BPN is still available, suggesting that it is the interpretation of the implicit reflexive argument of bare BPNs that is affected by these abstract predicates.

$$
\begin{aligned}
& \text { Zhangsan }_{\mathrm{j}} \text { lijie/yanjiu/renshi/xiangxin/zanshang ta-ziji }{ }_{\mathrm{j}} \text { de shou } \\
& \text { Zhangsan understand/study/know/believe/admire him-self DE hand } \\
& \text { de zuoyong. } \\
& \text { DE function } \\
& \text { 'Zhangsan understood/studied/knew/believed the function of his hand.' }
\end{aligned}
$$

The incompatibility between body-part RNs with an implicit possessor and abstract predicates that license logophoricity thus may contribute to the incompatibility between bare body-part RNs with an implicit possessor and logophoricity. 
The third conjecture concerns the following critical difference between KNs and BPNs: KNs can be frequently used as vocatives (66), whereas BPNs are usually not - although possible. ${ }^{25}$
$\mathrm{Ba} / \mathrm{Ma} / \mathrm{Jie} / \mathrm{Erzi}$, ni guolai. dad/mom/older-sister/son you come 'Dad/Mom/Older-sister/Son, you come here.'

When KNs such as ba/ma/jie/erzi 'dad/mom/older sister/son' are used as vocatives, they refer to the speaker's dad, mom, older sister or son. Vocative use is therefore based on the perspective of the speaker as the logophoric center. This may tie together KNs with logophors from a historical, grammaticalization perspective, distinguishing KNs from BPNs in their logophoric properties: since KNs are frequently associated with a perspective center, the implicit argument of KNs is more tightly connected to the simplex reflexive in Chinese, which can be used as a logophor; by contrast, BPNs are not usually tied to a logophoric center.

While the above three conjectures provide potential explanations for some of the differences we observed between the implicit arguments of BPNs and KNs, these explanations still require further research.

\section{Conclusions and future directions}

The current study provided evidence that bare inalienable relational nouns (RNs) have a syntactically represented implicit reflexive argument, and that the implicit arguments of these RNs are of two types. Body-part nouns/BPNs have a locally bound reflexive as their implicit possessor argument, whereas kinship nouns/KNs bear a reflexive argument that must be either locally or long-distance bound. Furthermore, these two types of implicit arguments of BPNs and KNs share important syntactic properties with the locally bound complex reflexive and the long-distance simple reflexive in Chinese, respectively. In addition, we presented evidence that body-part RNs are not compatible with logophoricity whereas KNs are. It is possible that it is the logophoric use that has led to long-distance binding for both the overt simple reflexives and the implicit possessor of KNs in Chinese, which leads us to the hypothesis that logophors and locally bound anaphors are in complementary distribution, providing independent novel support for studies that impose a dividing line between local and long-distance reflexives, including Reuland (2001), Huang \& Liu (2001), and more recently Charnavel \& Sportiche (2016). Finally, since this study has provided some evidence for the claim that the implicit argument of BPNs is not pronominal, analyses that build upon the assumption that such implicit argument is pronominal (e.g. Reuland \& Winter 2009) have to work around the problem and explain why such a pronoun argument (as these analyses

[25] We thank Sze Wing Tang for pointing out this difference to us. 
assume) cannot carry (disjoint) reference independently from an antecedent, which is an important characteristic of typical pronouns.

As for the cross-linguistic significance of this study, we would like to mention that BPNs and KNs in Norwegian share similar distinctions to the ones we observed in Chinese, namely, the former must be locally bound, and the latter can be either locally or long-distance bound. For instance, the contrast shown in (67) supports the argument that BPNs such as håret 'hair' must be locally bound whereas KNs such as faren 'father' can be either locally or long-distance bound (Lødrup, personal communication, 24 March 2017; see also Lødrup 1999, 2014).

(a) $\operatorname{Hun}_{\mathrm{j}}$ sa at $\mathrm{John}_{\mathrm{k}}$ vasket håret $*_{\mathrm{j} / \mathrm{k}}$.

she said that John washed hair.DEF

'She said that John washed his hair.'

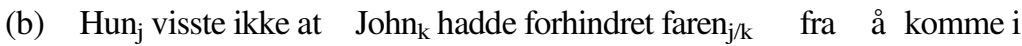

She knew not that John had prevented father.DEF from to coming to selskapet.

party.DEF

'She did not know that John had prevented her/his father from coming to the party.'

We hope that the distinctive properties of the implicit arguments of BPNs and KNs that we observed here can substantially inform future research involving a detailed cross-linguistic comparison of these properties. Future studies may also benefit from more investigation about binding and logophoricity in other languages that allow bare RNs, including but not limited to Japanese, Korean, Norwegian, Portuguese and Spanish.

\section{REFERENCES}

Alexiadou, Artemis. 2003. Some notes on the structure of alienable and inalienable possessors. In Coene \& D'hulst (eds.), 167-188.

Asudeh, Ash. 2005. Relational nouns, pronouns, and resumption. Linguistics and Philosophy 28.4, 375-446.

Barker, Chris. 1995. Possessive descriptions. Stanford, CA: CSLI Publications.

Bouchard, Denis. 1982. On the content of empty categories. Ph.D. dissertation, MIT.

Bresnan, Joan, Ash Asudeh, Ida Toivonen \& Stephen Wechsler. 2016. Lexical-functional syntax, 2nd edn. Malden, MA \& Oxford: John Wiley \& Sons.

Chappell, Hilary. 1996. Inalienability and the personal domain in Mandarin Chinese discourse. In Hilary Chappell \& William McGregor (eds.), The Grammar of inalienability: A typological perspective on body part terms and the part-whole relation, 465-527. Berlin \& New York: De Gruyter Mouton.

Chappell, Hilary \& William McGregory (eds.). 1996. The grammar of inalienability: A typological perspective on body part terms and the part-whole relation. Berlin \& New York: De Gruyter Mouton.

Charnavel, Isabelle. 2017. Anaphora and logophoricity. Ms., Harvard University. https://piazza.com/ huji.ac.il/fall2017/syn/resources (accessed 20 April 2018).

Charnavel, Isabelle, C.-T. James Huang, Peter Cole \& Gabriella Hermon. 2017. Long-distance anaphora: Syntax and discourse. In Martin Everaert \& Henk C. van Riemsdijk (eds.), The Wiley Blackwell companion to syntax, 1-82. Hoboken, NJ: John Wiley \& Sons.

Charnavel, Isabelle \& Yujing Huang. 2018. Inanimate ziji and Condition A in Mandarin. In Wm. G. Bennett, Lindsay Hracs \& Dennis Ryan Storoshenko (eds.), Proceedings of the 35th West Coast Conference on Formal Linguistics (WCCFL 35), 132-141. Somerville, MA: Cascadilla Press. 


\section{INALIENABLE RELATIONAL NOUNS IN CHINESE}

Charnavel, Isabelle \& Dominique Sportiche. 2016. Anaphor binding: What French inanimate anaphors show. Linguistic Inquiry 47.1, 35-87.

Charnavel, Isabelle \& Christina Diane Zlogar. 2015. English reflexive logophors. Presented at The Fiftyfourth Annual Meeting of the Chicago Linguistic Society (CLS 51).

Chen, Hsiang-Yun. 2018. De se marking, logophoricity, and ziji. In Minyao Huang \& Kasia M. Jaszczolt (eds.), Expressing the self: Cultural diversity and cognitive universals, 88-125. Oxford: Oxford University Press.

Cheng, Gong. 1999. Hanyu 'ziji’ yici de xingzhi [On the nature of ziji in Chinese]. Dangdai Yuyan Xue [Contemporary Linguistics] 2, 33-43.

Cheng, Lisa Lai-Shen \& Elizabeth Ritter. 1987. A small clause anaiysis of inalienable possession $\mathrm{m}$ Mandarin and French. North-Eastern Linguistic Society 18 (NELS 18), 65-78.

Chomsky, Noam. 1981. Lectures on Government and Binding. Dordrecht: Foris.

Chomsky, Noam. 1986. Knowledge of language: Its nature, origin, and use. New York: Praeger.

Clements, George N. 1975. The logophoric pronoun in Ewe: Its role in discourse. Journal of West African Languages 10.2, 141-177.

Coene, Martine \& Yves D'hulst. 2003. From NP to DP: The expression of possession in noun phrases, vol. 2: The expression of possession in noun phrases. Philadelphia, PA: John Benjamins.

Cole, Peter, Gabriella Hermon \& C.-T. James Huang (eds.). 2001. Long-distance reflexives (Syntax and Semantics 33). San Diego, CA: Academic Press.

Cole, Peter, Gabriella Hermon \& Cher Leng Lee. 2001. Grammatical and discourse conditions on long distance reflexives in two Chinese dialects. In Cole et al. (eds.), 1-46.

Cole, Peter \& Li-May Sung. 1994. Head movement and long-distance reflexives. Linguistic Inquiry 25.3, 355-406.

Dong, Xiufang. 2002. Gu Hanyu de 'zi' and 'ji'-Xiandai Hanyu 'ziji' de teshuxing de laiyuan [ $Z i$ and $j i$ in Ancient Chinese: The origin of peculiarities of ziji in Modern Chinese]. Gu Hanyu Yanjiu [Ancient Chinese Studies] 1, 69-75.

Fox, Barbara A. 1981. Body part syntax: Towards a universal characterization. Studies in Language 5.3, 323-342.

Guéron, Jacqueline. 1985. Inalienable possession, PRO-inclusion and lexical chains. In Jacqueline Guéron, Hans-Georg Obenauer \& Jean-Yves Pollock (eds.), Grammatical representation, 43-86. Dordrecht: Foris.

Guéron, Jacqueline. 1992. Inalienable possession and locative aspect. In Joseba A. Lakarra \& Jon Ortiz de Urbina (eds.), Supplements of ASJU 27: Syntactic theory and Basque syntax (International Journal of Basque Lingusitics and Philology XXVII), 135-146.

Guéron, Jacqueline. 2003. Inalienable possession and the interpretation of determiners. In Coene \& D'hulst (eds.), 189-220.

Guéron, Jacqueline. 2006. Inalienable possession. In Martin Everaert \& Henk van Riemsdijk (eds.), The Blackwell companion to syntax, vol. I, 589-638. Malden, MA: Blackwell.

Hestvik, Arild. 1995. Reflexives and ellipsis. Natural Language Semantics 3.2, 211-237.

Heycock, Caroline. 1995. Asymmetries in reconstruction. Linguistic Inquiry 26.4, 547-570.

Hicks, Glyn. 2009. The derivation of anaphoric relations. Amsterdam: John Benjamins.

Hornstein, Norbert. 2003. On control. In Randall Hendrick (ed). Minimalist syntax, 6-81. Melden, MA: Blackwell.

Hsieh, Miao-Ling. 2001. Form and meaning: Negation and question in Chinese. Ph.D. dissertation, University of Southern California.

Huang, C.-T. James. 1982. Logical relations in Chinese and the theory of grammar. Ph.D. dissertation, MIT.

Huang, C.-T. James. 1989. Pro-drop in Chinese: A generalized control theory. In Osvaldo A. Jaeggli \& Kenneth J. Safir (eds.), The null subject parameter, 185-214. Dordrecht: Kluwer.

Huang, C.-T. James. 1991. Remarks on the status of the null object. In Robert Freidin (ed.), Principles and parameters in comparative grammar, 56-76. Cambndge, MA: MIT Press.

Huang, C.-T. James. 1993. Reconstruction and the structure of VP: Some theoretical consequences. Linguistic Inquiry 24.1, 103-138.

Huang, C.-T. James, Yen-Hui Audrey Li \& Yafei Li. 2009. The syntax of Chinese. Cambridge: Cambridge University Press.

Huang, C.-T. James \& C.-S. Luther Liu. 2001. Logophoricity, attitudes, and ziji at the interface. In Cole et al. (eds.), 141-195. 


\section{ALAN HEZAO KE \& ACRISIO PIRES}

Huang, C.-T. James \& Chih-Chen Jane Tang. 1991. The local nature of the long-distance reflexive in Chinese. In Jan Koster \& Eric Reuland (eds.), Long distance anaphora, 263-282. Cambridge: Cambridge University Press.

Ke, Alan Hezao, Ya Zhao, Liqun Gao, Shuying Liu \& Acrisio Pires. 2019. On the implicit anaphoric argument of relational nouns in Mandarin Chinese. Journal of Psycholinguistic Research 48.4, 819-842.

Kim, Ji-Hye \& James H. Yoon. 2009. Long-distance bound local anaphors in Korean: An empirical study of the Korean anaphor caki-casin. Lingua 119.5, 733-755.

Klokeid, Terry Jack. 1976. Topics in Lardil grammar. Ph.D. dissertation, MIT.

Lebeaux, David. 1985. Locality and anaphoric binding. The Linguistic Review 4.4, 343-364.

Li, Yen-Hui Audrey \& Ting-Chi Wei. 2014. Ellipsis. In C.-T. James Huang, Yen-Hui Audrey Li \& Andrew Simpson (eds.), The handbook of Chinese linguistics, 275-310. Malden, MA: Blackwell.

Lødrup, Helge. 1999. Inalienables in Norwegian and binding theory. Linguistics 37.3, 365-388.

Lødrup, Helge. 2014. Split possession and the syntax of kinship nouns in Norwegian. The Journal of Comparative Germanic Linguistics 17.1, 35-57.

Martí, Luisa. 2006. Unarticulated constituents revisited. Linguistics and Philosophy 29.2, 135-166.

Martí, Luisa. 2015. Grammar versus pragmatics: Carving nature at the joints. Mind \& Language 30.4, 437-473.

Nakamoto, Takeshi. 2010. Inalienable possession constructions in French. Lingua 120.1, 74-102.

Niu, Fangfang. 2016. Juxtaposed possessives ta baba 'her/his father' in Mandarin Chinese. Lingua 183, 53-85.

Pan, Haihua. 1995. Locality, self-ascription, discourse prominence, and Mandarin reflexives. $\mathrm{Ph} . \mathrm{D}$. dissertation, The University of Texas at Austin.

Pan, Haihua. 1998. Closeness, prominence, and binding theory. Natural Language \& Linguistic Theory 16.4, 771-815.

Pan, Haihua. 2001. Why the blocking effect? In Cole et al. (eds.), 279-316.

Partee, Barbara H. 1983/1997. Uniformity vs. versatility: The genitive, a case study (appendix to Theo Janssen 1997). In Johan van Benthem \& Alice ter Meulen (eds.), The handbook of logic and language, 464-470. Amsterdam: Elsevier.

Partee, Barbara H. 2004. Compositionality in formal semantics: Selected papers of Barbara H. Partee. Oxford: Blackwell.

Partee, Barbara H. \& Vladimir Borschev. 2003. Genitives, relational nouns, and argument-modifier ambiguity. In Ewald Lang, Claudia Maienborn \& Cathrine Fabricius-Hansen (eds.), Modifying adjuncts, 67-112. Berlin: Mouton de Gruyter.

Pires, Acrisio. 2006. The minimalist syntax of defective domains: Gerunds and infinitives. Amsterdam \& Philadelphia, PA: John Benjamins.

Reinhart, Tanya \& Eric Reuland. 1993. Reflexivity. Linguistic Inquiry 24.4, 657-720.

Reuland, Eric. 2001. Primitives of binding. Linguistic Inquiry 32.3, 439-492.

Reuland, Eric. 2011. Anaphora and language design. Cambridge: MIT Press.

Reuland, Eric \& Dagmar Schadler. 2010. Approaching body part reflexives. Presented at The Afranaph Project Development Workshop I, Rutgers University, New Brunswick, 10-11 December.

Reuland, Eric \& Yoad Winter. 2009. Binding without identity: Towards a unified semantics for bound and exempt anaphors. In Sobba Lalitha Devi, António Branco \& Ruslan Mitkov (eds.), Proceedings of the 7th Discourse Anaphora and Anaphor Resolution Colloquium (DAARC), 69-79. Berlin: Springer.

Ritter, Elizabeth \& Sara Thomas Rosen. 2014. Possessors as external arguments: Evidence from Blackfoot. In J. Randolph Valentine \& Monica Macaulay (eds.), Papers of the Forty-second Algonquian Conference, 211-229. Albany, NY: SUNY Press.

Ross, John R. 1970. On declarative sentences. In Roderick A. Jacobs \& Peter S. Rosenbaum (eds.), Readings in English transformational grammar, 222-272. Waltham, MA: Ginn.

Rudnev, Pavel. 2017. Minimal pronouns, logophoricity and long-distance reflexivisation in Avar. Studia Linguistica 71.1-2, 154-177.

Sag, Ivan A. 1976. Deletion and logical form. Ph.D. dissertation, MIT.

Schladt, Mathias. 2000. The typology and grammaticalization of reflexives. In Zygmunt Frajzyngier \& Traci Walker (eds.), Reflexives: Form and function, vol. 1 (Typological Studies in Language 40), 103-124. Amsterdam: John Benjamins.

Sells, Peter. 1987. Aspects of logophoricity. Linguistic Inquiry 18.3, 445-479. 


\section{INALIENABLE RELATIONAL NOUNS IN CHINESE}

Shapiro, Lewis P. \& Arild Hestvik. 1995. On-line comprehension of VP-ellipsis: Syntactic reconstruction and semantic influence. Journal of Psycholinguistic Research 24.6, 517-532.

Soh, Hooi Ling. 2007. Ellipsis, last resort, and the dummy auxiliary shi 'be' in Mandarin Chinese. Linguistic Inquiry 38.1, 178-188.

Stanley, Jason. 2000. Context and logical form. Linguistics and Philosophy 23.4, 391-434.

Stanley, Jason. 2002. Making it articulated. Mind \& Language 17.1-2, 149-168.

Stanley, Jason. 2004. On the linguistic basis for contextualism. Philosophical Studies 119.1, 119-146.

Stanley, Jason \& Gendler Z. Szabó. 2000. On quantifier domain restriction. Mind \& Language 15.2-3, 219-261.

Vergnaud, Jean-Roger \& Maria Luisa Zubizarreta. 1992. The definite determiner and the inalienable constructions in French and in English. Linguistic Inquiry 23.4, 595-652.

Vikner, Carl \& Per Anker Jensen. 2002. A semantic analysis of the English genitive: Interaction of lexical and formal semantics. Studia Linguistica 56.2, 191-226.

Wang, Yingying \& Haihua Pan. 2014. A note on the non-de se interpretation of attitude reports. Language 90.3, 746-754.

Wang, Yingying \& Haihua Pan. 2015. Empathy and Chinese long distance reflexive ziji-remarks on Giorgi (2006, 2007). Natural Language \& Linguistic Theory 33.1, 307-322.

Wei, Ting-Chi. 2009. The focal structure in Mandarin VP-ellipsis: A cross-linguistic perspective. Taiwan Journal of Linguistics 7.1, 85-119.

Williams, Edwin. 1977. Discourse and logical form. Linguistic Inquiry 8.1, 101-139.

$\mathrm{Xu}$, Liejiong. 2003. Remarks on VP-ellipsis in disguise. Linguistic Inquiry 34.1, 163-171.

Xue, Ping, Carl Pollard \& Ivan A. Sag. 1994. A new perspective on Chinese ziji. In Raul Aranovich, William Byrne, Susanne Preuss \& Martha Senturia (eds.), The proceedings of the Thirteenth West Coast Conference on Formal Linguistics (WCCFL 13), 432-447. Stanford, CA: CSLI Publication. $\mathrm{Yu}$, William Xian-Fu. 1996. A study of Chinese reflexives. Ph.D. dissertation, University of London.

Zhang, Niina Ning. 2009. The syntax of relational-nominal second constructions in Chinese. Yuyanxue Luncong [Essays on Linguistics] 39, 257-301. Beijing: Shangwu Yingshu Guan.

Authors' addresses: $\quad(\mathrm{Ke})$

Department of Linguistics, Languages, and Cultures, Michigan State University, $B$-230 Wells Hall,

East Lansing, MI 48824, USA

kehezao@msu.edu

(Pires)

Department of Linguistics, University of Michigan, Ann Arbor, 458 Lorch Hall, 611 Tappan Street, Ann Arbor, MI 48109-1220, USA

pires@umich.edu 